\title{
The Evolution of Mathematics in
} Ancient China: From the Newly Discovered Shu and Suan shu shu Bamboo Texts to the Nine Chapters on the Art of Mathematics"

\author{
by Joseph W. Dauben ${ }^{\ddagger}$
}

The history of ancient Chinese mathematics and its applications has been greatly stimulated in the past few decades by remarkable archaeological discoveries of texts from the pre-Qin and later periods that for the first time make it possible to study in detail mathematical material from the time at which it was written. By examining the recent Warring States, Qin, and Han bamboo mathematical

\footnotetext{
* (c) 2014 Joseph W. Dauben. Used with permission.

$\dagger$ This article is based on a lecture presented in September of 2012 at the Fairbank Center for Chinese Studies at Harvard University, which was based on a lecture first given at National Taiwan Tsinghua University (Hsinchu, Taiwan) in the Spring of 2012. I am grateful to Thomas Lee of National Chiaotung University of Taiwan where I spent the academic year 2012 as Visiting Research Professor at Chiaota's Institute for Humanities and Social Sciences, which provided support for much of the research reported here, and to Shuchun GUO, Wannsheng HORNG, Kwangtai HSU, Alexei Volkov, and Dahai ZOU for helpful comments that have been incorporated in the version of the lecture published here. Readers should note that throughout the text, the order of Chinese names follows the convention of the ICCM Notices, with family names following given names; historical names prior to the twentieth century, however, are given in their usual Chinese order, i.e. LIU Hui and SIMA Qian, with the family name given in capital letters.

$\ddagger$ Department of History, Herbert H. Lehman College, City University of New York; and Ph.D. Program in History, The Graduate Center, City University of New York

E-mail: jdauben@gc.cuny.edu
}

texts currently being conserved and studied at Tsinghua University and Peking University in Beijing, the Yuelu Academy in Changsha, and the Hubei Museum in Wuhan, it is possible to shed new light on the history of early mathematical thought and its applications in ancient China. Also discussed here are developments of new techniques and justifications given for the problems that were a significant part of the growing mathematical corpus, and which eventually culminated in the comprehensive Nine Chapters on the Art of Mathematics.

\section{Contents}

1 Recent Archaeological Excavations: The Shu and Suan shu shu . . . . . . . . . . . . . . . 25

2 Log-in-the-Wall/Reed-in-a-Pond Problems .. 28

3 Extraction of Roots in the Suan shu shu Versus the Nine Chapters . . . . . . . . . . . . . . 34

4 Three Multi-Tasking Problems: Traps for the Unwary Student . . . . . . . . . . . . . . . . 36

5 Archimedes and LIU Hui on Circles and Spheres . . . . . . . . . . . . . . 39

6 Conclusion . . . . . . . . . . . . . . . . 47

7 Glossary . . . . . . . . . . . . . . . . . . 48

8 References . . . . . . . . . . . . . . . . . . . 49 


\section{Recent Archaeological Excavations}

\section{4-The Terracotta Army}

In the spring of 1974 farmers digging a well to the east of Mount Li in the suburbs of Xi'an in Shaanxi Province discovered the remains of a terracotta figure that soon led to one of the greatest archaeological finds of the $20^{\text {th }}$ century. The site proved to be the mausoleum of the First Qin Emperor, Qin Shi Huang, who died in 210 BCE. According to the Western Han dynasty historian SIMA Qian (145-90 BCE), writing only a century later, construction of the gravesite began in 246 BCE and involved more than 700,000 workers. It is estimated that the necropolis covers more than two-million square meters, whereas the tomb itself occupies only about a tenth of this, or very nearly an area measuring 485 by 514 meters, a total of approximately 220,000 square meters which has yet to be excavated. To date, three pits of terracotta warriors have been studied, roughly 20,000 spare meters containing more than 8,000 life-sized warriors.

According to SIMA Qian, the site includes-in addition to the army and important officials-vast palaces, scenic towers, valuable utensils, and "wonderful objects," reportedly with a ceiling studded with pearls and precious gems to represent the heavens, the stars and planets, while below, on the ground, major features of the emperor's terrestrial realm were depicted, including mountains and one-hundred rivers flowing with mercury. Preliminary soundings have indeed discovered higher than normal amounts of mercury on the site.

Less dramatic, but no less important to historians of science, have been a number of archaeological discoveries in China over the past seventy-five years or so that have served to expand considerably our understanding of the history of ancient Chinese mathematics. Until recently, the only known sources available for study have been limited primarily to the socalled Ten Classics of Chinese Mathematics as embodied in texts like the Zhou bi suan jing, the Jiu zhang suan shu, Hai dao suan jing, Sunzi suan jing, and a handful of other texts. These were printed in an edition that has partly survived from the Southern Song dynasty, based on versions of ancient works that were gathered together by LI Chunfeng and his associates in the Tang dynasty, when ten works, subsequently known as the "Ten Classics," were designated as the basic texts students were expected to master in order to pass imperial examinations.

\section{4-The Chu Silk Manuscript. State of Chu, Warring States Period}

The Chu boshu is actually a document on silk unearthed by two grave robbers looting a tomb probably sometime shortly before the end of World War II and China's War of Resistance against Japan and its own civil war. This was near Zidanku, east of Changsha in Hunan Province. The Chu manuscript was later traced by archaeologists to a location that dated it to around 300 BCE. In 1946 Jixiang CAI, an art collector in China, entrusted the document to the Yale-trained sinologist and collector, John Hadley Cox, who took the document to the United States where it was exhibited at the Metropolitan Museum of Art in New York City. Although offered to the Museum for its own collection, the Trustees were not sufficiently impressed by the document to authorize its acquisition. In 1965 it was purchased by the New York psychiatrist and philanthropist/collector Arthur M. Sackler, who presented the document to the Freer Gallery in Washington, D.C. There the document was restored and photographed the following year using infrared technology, which greatly enhanced the legibility of the characters, making the text substantially easier to read. In 1967 an international symposium was held at Columbia University where forty leading sinologists, anthropologists, archaeologists, and art experts met to study and discuss the Chu manuscript (see p. 26).

Basically, the text deals with astronomy, astrology, motions of the heavens, changes of the seasons, as well as descriptions of auspicious or inauspicious days. It mentions the legendary Fuxi and Nuwa, and includes depictions of deities associated with the twelve months. Fuxi and Nuwa are the mythical figures associated with the creation of mathematics in ancient China and the overall content of the Chu manuscript attests to the pervasive importance of mathematics in a diverse number of different applications in ancient China. For example, the following explains a number of different ways in which mathematics figures in the Chu silk manuscript:

\begin{abstract}
If $[\ldots]$ and the length of the lunar months become too long or too short, then they will not fit the proper degree and spring, summer, autumn, and winter will [not] be [...] regular; the sun, moon, and planets will erratically overstep their paths. When (the months) are too long, too short, contrary, or chaotic, (the growth of) the grasses and trees have no regularity. This is [called] yao, "demonic" (influences or omens). When heaven and earth create calamities, the Heaven's Cudgel (Tianpou) star creates (sweeping) destruction, sending (the destruction) down through all four regions (of the earth). Mountains collapse, springs gush forth geysers. This is called "contravention." If you contravene the years (and) the months, then upon entering the seventh or eighth day of the month there will be fog, frost, and clouds of dust, and you will not be able to function according (to heaven's plan) (Li and Cook 1999: 174).
\end{abstract}

Here mathematics regulates and harmonizes the motions and transformations of both the heavens and earth, in ways reminiscent of what Heraclitus says of the motion of the Sun, that must also heed 


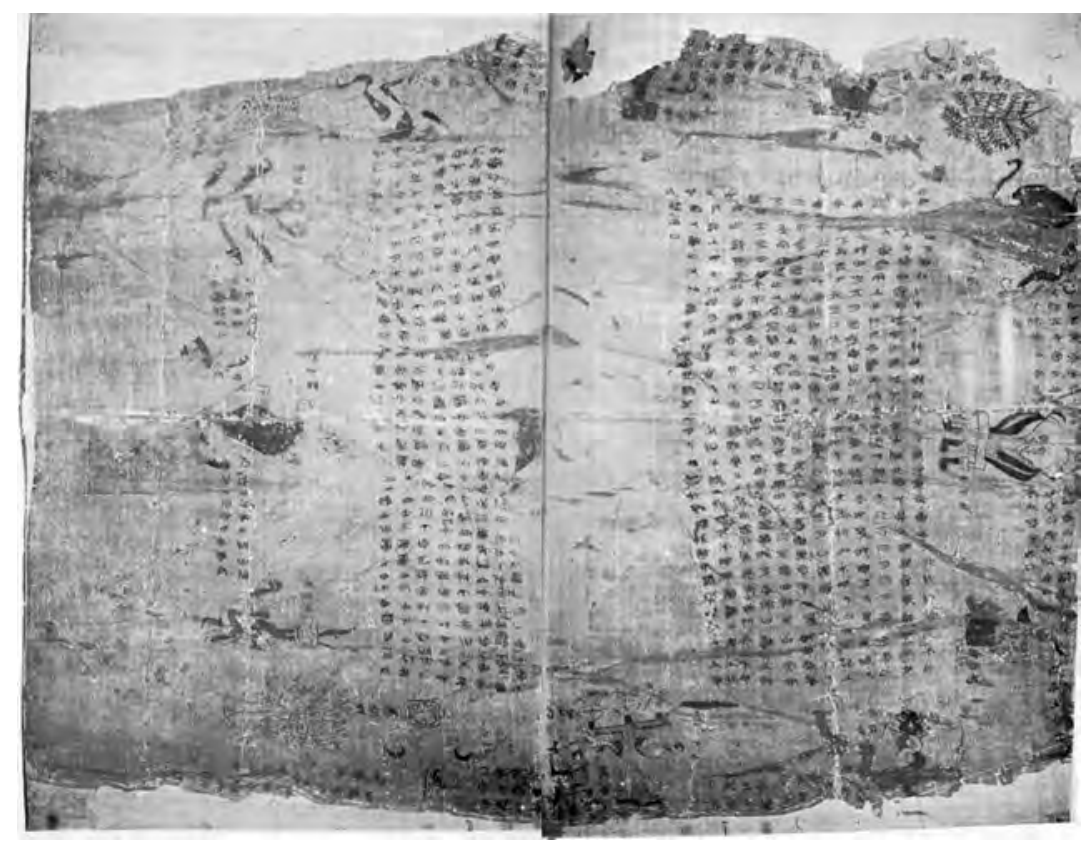

Infrared photograph of the Chu silk manuscript (Freer Gallery, Washington, DC).

the limits set by the fates: "The sun will not overstep his measures; if he does, the Erinyes, the handmaids of Justice, will find him out" (Plutarch, On exile, $604 \mathrm{AB}$, quoted from Burnet 1912, Fragment 94), see also (Kirk 1954).

\section{2-1974: Mawangdui. Changsha, Hunan (186-168 BCE)}

From 1972 to 1974 , three tombs dating to the early Western Han dynasty were excavated at Mawangdui also near Changsha in Hunan Province. The tombs have been identified as those of LI Cang, the first Marquis of Dai and Chancellor to the Prince of the State of Changsha; of XIN Zhui, LI Cang's wife, the Marquise of Dai; and of their son (conjectured), who died at an early age.

Along with the remarkably well-preserved body of XIN Zhui found in Tomb No. 1, an ornate series of nested coffins was unearthed, along with boxes containing more than 1,000 cultural relics covering an area of some 6.8 square meters. Although Tomb No. 2, dated to 186 BCE, the year the Marquis LI Cang died, had been plundered, Tomb No. 3 produced 40 paintings and manuscripts on silk, bamboo and wooden slips, including lost and previously unknown works. The tomb itself is dated to $168 \mathrm{BCE}$, the year its occupant, a male in his 30 s and presumed to be the Marquis' son, died. Among the subjects treated in the materials from Tomb No. 3 are history, politics, economics, military affairs, physical training and exercises, philosophy, astronomy, geography, medicine, and literature.
In addition to one of the earliest copies of the Zhou yi found in Tomb No. 3, there are the famous Mawangdui maps depicting the Kingdoms of Changsha and Nanyue, as well as a work on medicine, Wu shi er bing fang (Prescriptions for 52 Diseases), giving recipes for drugs and treatments for 52 diseases, including 254 medicines, 283 prescriptions, and descriptions of moxibustion, acupuncture, and even surgical procedures. For the history of astronomy there is an important text, Divination by Astrological and Meteorological Phenomena, that includes some 250 drawings of clouds, rainbows, stars and comets, with captions recording their names and giving brief explanations of their divinatory significance. Among the two-dozen or so renderings of comets, each is pictured and described briefly, as for example appearing at "the death of the prince," heralding "the coming of the plague," or marking "a 3-year drought."

Another work, Divination by Five Stars, includes one part by the same title devoted to astrology, and another part, "Diagrams of the Movements of Five Stars," which is a record of the motions of the five planets recording their relative positions for the years 246-177 BCE. Much of the data recorded here is remarkably accurate. The documents unearthed at Mauwangdui are especially useful to historians of mathematics interested in the ancient system of weights and measures and applications of such methods as the Rule of Three in carrying out the commercial transactions of everyday life. For recent works drawing on material from Mawangdui, see (Hulswé 1981), (Zou 2007a and 2007b), and (Dauben 2008: 137-139). 


\section{5-Qin Bamboo Slips from Shuihudi}

In December of 1975 the tomb of a Qin dynasty administrator was excavated by archaeologists working at Shuihudi in Yunmeng County, Hubei Province. The texts recovered from Tomb No. 11 concern primarily Qin laws and public documents, and cover matters related to government, economics, culture, law, military affairs, and the like. It turns out that these materials can be very helpful to historians of mathematics in understanding not only the calculations of exchange rates for various commodities, as given for example in Chapter II of the Nine Chapters on the Art of Mathematics, Su mi (Millet and Rice/Grains), but also in determining the meaning of certain terms for different qualities and levels of refinement of rice and millet, as well as anomalies in the treatment of how exchanges are computed in different works, for example in the Suan shu shu and the Nine Chapters. Again, see for example (Hulswé 1981), (Zou 2007a and 2007b), and (Dauben 2008: 137-139). Further analysis of how the comparative study of more recently discovered works may help shed new light on such matters follows below.

\section{3-Han Bamboo Slips from Zhangjiashan}

In December and January of 1983-1984, archaeologists excavating the tomb of a Qin dynasty provincial administrative bureaucrat at a Western Han Dynasty site near Zhangjiashan in Jiangling County, Hubei Province, discovered a number of books on bamboo strips, including inter alia works on legal statutes, military practice, and medicine. Among these was a previously unknown mathematical work on some 200 bamboo slips, the Suan shu shu, or Book

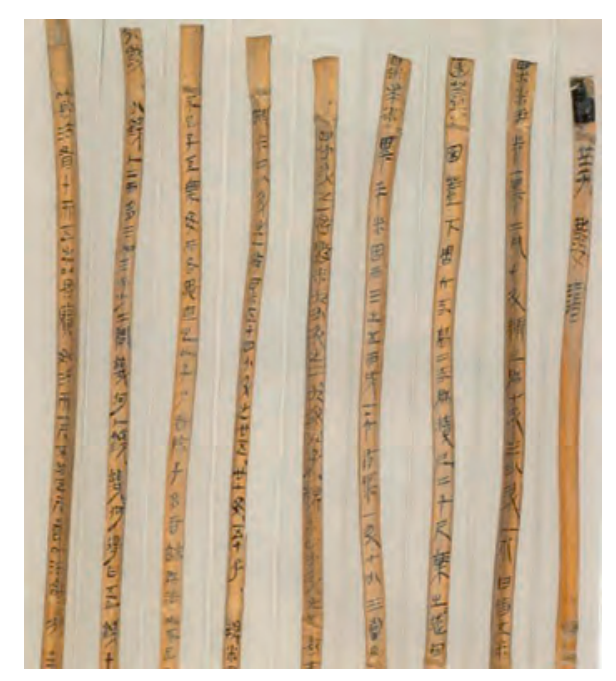

Bamboo strips of the Suan shu shu; the title of this work appears at the top of the right-most strip above. of Numbers and Computations. Based upon other works found in the tomb, especially a copy of the $E r$ nian lü ling (Laws and Decrees of the Second Year (of the Empress LÜ Hou)), archaeologists date the tomb to ca. 186 BCE, LÜ Hou's regency having lasted from 188 to 180 BCE. The Suan shu shu is the earliest yet discovered work devoted specifically to mathematics in ancient China from a dated excavated context. For a detailed comparison of the Suan shu shu with the Nine Chapters, see (Cullen 2004) and (Dauben 2008). In Sections 3 and 4 below, several particular problems are examined from the Book of Numbers and Computations.

\section{2-Liye Ancient City Qin Dynasty Bamboo Documents}

In April of 2002, with the immanent construction of the Wanmipo Hydropower Station at Liye, Longshan County, Hunan Province, the Hunan Institute of Archaeology and Cultural Relics was again called upon to excavate a site of approximately 20,000 square meters just to the east of the Youshui river. In addition to an ancient city wall, the site included wells and tombs from which more than 30,000 bamboo strips and wooden tablets have been preserved. Among these Ancient Well No. 1 was particularly valuable, and yielded documents recording political, economic, military, cultural, and social events of the Warring States period through the Qin and Han dynasties. In particular, the Qin dynasty annual calendars found at Liye provide fairly complete records, day by day, for the years 221-206 BCE.

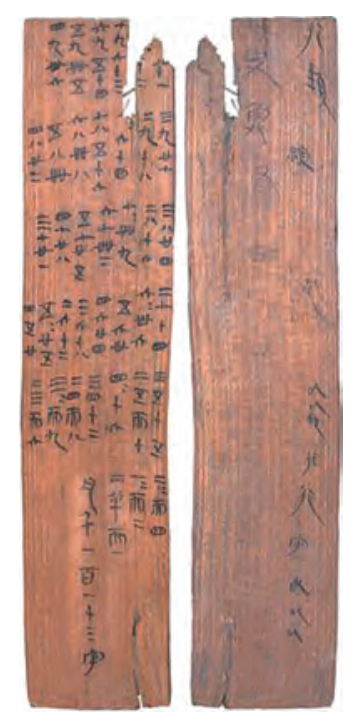

Multiplication table. Excavated: April, 2002; Qin Dynasty (221 BCE-206 BCE); Length $22 \mathrm{~cm}$ width $4.5 \mathrm{~cm}$. 
Of particular interest for the history of mathematics is a Qin dynasty multiplication table, on a board measuring $22 \mathrm{~cm}$ by $4.5 \mathrm{~cm}$. This bears direct comparison with similar multiplication tables that comprise the opening portion of the Suan shu shu. For details, see (Peng Hao 2000 and 2001), (Cullen 2004), and (Dauben 2008).

\section{7-Qin Slips Collected by the Yuelu Academy}

In December of 2007 the Yuelu Academy of Hunan University purchased a group of more than 1300 Qin dynasty mostly bamboo but some wooden slips from an antiquities dealer in Hong Kong. A preliminary survey of the entire collection indicates that there are at least six different works among the bamboo and wooden slips in the Yuelu Academy's collection. Of these, on the back of bamboo strip [0956] is the character $S h u$ (Numbers), which serves as the title of a collection of mathematical problems comprised of 231 complete bamboo slips, along with some partial slips. A recent transcription of this work indicates that there are 73 computational problems in all, with 60 solution methods (Xiao Can 2010). One problem in particular from the $S h u$ is discussed in further detail below.

\section{8-Tsinghua University (Beijing) Bamboo Slips}

In 2008 Tsinghua University in Beijing acquired a collection of 2388 bamboo slips, including a number of fragments, all ascribed to the Warring States period and later, by radiocarbon analysis, dated more precisely to $305 \pm 30 \mathrm{BCE}$. The entire lot was purchased from an antiquities dealer in Hong Kong, and came with what is presumed to be the box in which the bamboo slips were originally found. The box, in both its style and decoration, is in keeping with this dating. The slips were severely damaged by water and mold, and steps were taken immediately to undertake their conservation by a team of experts headed by Professor Xueqin LI at Tsinghua's Center for Excavated Texts Research and Preservation. The Center was established in April of 2009, shortly after the donation was made to Tsinghua University. It is assumed that the bamboo slips were taken from a tomb in Hubei or Hunan Province, and subsequently found their way to the dealer in Hong Kong from whom they were purchased.

For the history of mathematics, however, the most remarkable of the Tsinghua bamboo collection is a set of 21 slips that provide an entire multiplication table from $1 / 4$ times $1 / 4$ to 9 times 9 , and then multiples of 10 from 10 to 90 (see p. 29). Other multiplication tables have been found separately on boards like the one from the ancient site at Liye (Hunan) in 2002, and another on a wooden tablet $22 \mathrm{~cm}$ long found at Gurendi, Zhangjiajie, Hunan Province, sometime between 1987 and 2004. This tablet contains a table beginning with "nine-times-nine" and continuing down to the multiplication of "one-times-one." The Suan shu shu also includes a number of slips devoted to multiplications, primarily of fractions as small as $1 / 9$ and powers of ten as large as $10^{7}$ (Feng and Xu 2013), (Berlin 2014), and (Qiu 2014).

\section{Log-in-the-Wall/Reed-in-a-Pond Problems. Comparing the Yuelu Academy's Shu with the Nine Chapters}

Having surveyed the mounting archaeological evidence, what light do the recently excavated materials related to ancient Chinese mathematics shed on

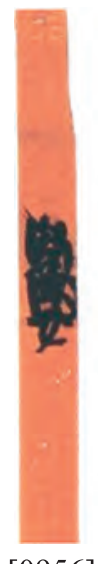

[0956]
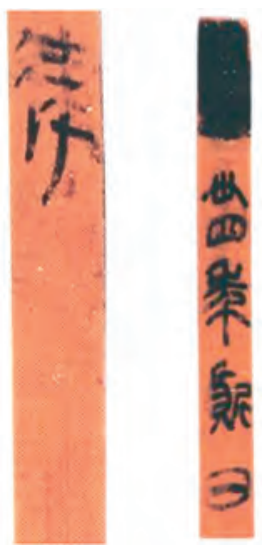
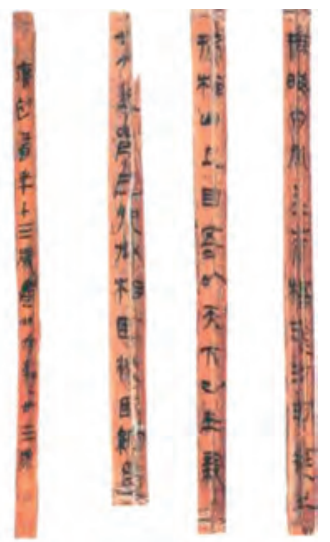

Bamboo slips among those constituting the mathematical work entitled Shu, preserved at the Yuelu Academy, Hunan University (Changsha, Hunan Province). 

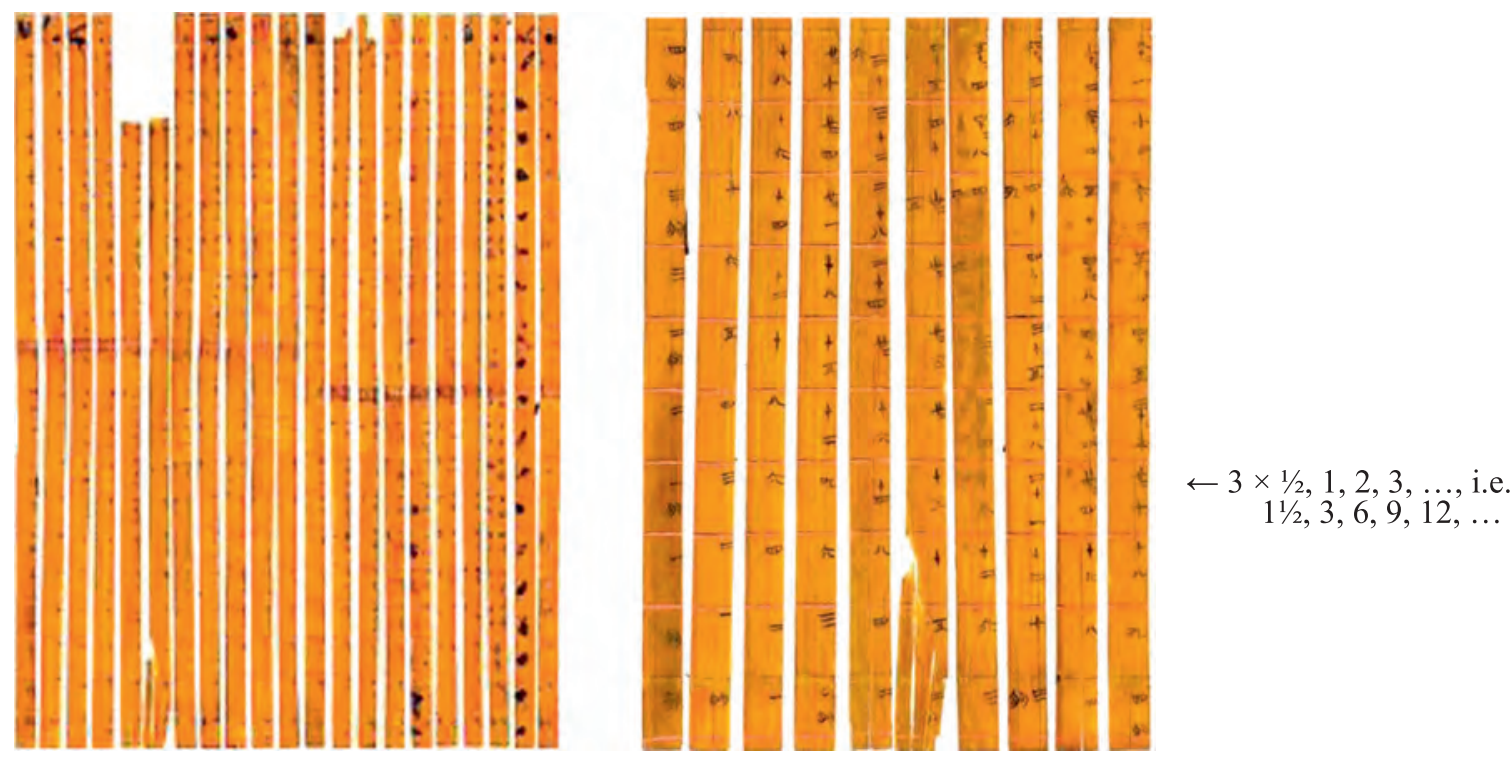

The twenty-one bamboo slips (left) comprising the Tsinghua multiplication table. The top row reads from left to right: $1 / 2,1,2,3, \ldots, 9,10,20, \ldots, 80,90$; the left-most strip reads from top to bottom: $90,80, \ldots, 20,10,9, \ldots, 3,2,1,1 / 2$. The enlarged portion on the right shows the lower-left quadrant of the table; the bottom row gives the multiples of 1/2; the fourth row from the bottom reading across, left to right, gives the multiples of three, i.e. $1 \frac{1 / 2}{2} 3,6,9,12, \ldots$.

the mathematical content of these documents and the ways in which mathematics developed and changed from pre-Qin to Eastern Han times? Of many examples that might be considered, the following problem related to the circle from the Yuelu Academy's Shu (Numbers), for which there is no counterpart in the Suan shu shu, reflects significant developments in the conceptualization of mathematics between the Shu and the Nine Chapters. Note that an internal reference in the $S h u$ to the reign of the Qin emperor dates the bamboo strips themselves to approximately 212 BCE. The Yuelu Academy's collection of bamboo strips related to mathematics has been studied in detail by scholars at Hunan University, and by Can XIAO in particular, whose table of contents from her thesis organizes the major content area of the Shu into the following ten categories (Xiao Can 2010).

1. Mathematical problems of rice field production and tax computations

2. Mathematical problems of calculating areas of farm land
3. Calculating exchanges of grains and commodities

4. Mathematical problems of proportional distribution

5. Mathematical problems of excess and deficiency

6. Mathematical problems of short widths

7. Mathematical problems of calculating volumes

8. Mathematical problems of gou-gu (right triangles)

9. Methods of stationing an army

10. Standards of Measurement

Number 8 of the above categories consists of one problem identified as "Mathematical problems of gou-gu." Whether this is accurately described as a gou-gu problem or not is problematic in that nothing in the statement of the problem mentions either gou or $g u$, although the solution of the problem, for reasons that will become apparent, clearly relate this problem to the gou-gu problems that constitute Chapter 9 of the Nine Chapters. In the Shu, the following problem runs across two bamboo strips, [0304] and [0457]:

\footnotetext{
口有圓材猩 (埋) 地, 不智 (知) 小大, 品之, 入材一寸而得平一尺, 問材周大幾可 (何)。即曰, 半平得五寸, 令相乘也, 以深 [0304] 一寸为法, 如法得一寸, 有 (又) 以深益之, 即材徑也。 [0457]
}

Suppose there is a circular [piece of] wood buried in the ground, whose size is unknown, but cutting to a depth of 1 cun gives a chord of $1 \mathrm{chi}$; it is asked how great is the circumference of the [circular piece of] wood? [It] says: half the chord is 5 cun, multiply it by itself and using the depth of 1 cun as the divisor, dividing gives the result in cun, again adding the depth [of the cut] gives the diameter of the wood. 
This problem basically reduces to a circle, for which the length of a chord and its sagitta are given, and from which the question is to determine the circumference of the circle (although the answer given is actually that for the diameter of the circle). The method only describes the steps of computation by which the answer is computed (where 1 chi $=10$ cun): square half the sagitta ( 5 cun), i.e. $25 \mathrm{cun}^{2}$; divide by the depth of the cut ( 1 cun), i.e. 25 cun; add the depth of the cut (1 cun), i.e. 26 cun. No explanation is given as to why these steps should be taken, and there is no argument to establish that the result is in fact correct. But note that the problem is presented in such a way that the method is introduced by two characters: 即曰 ji yue (it says). We shall return to the significance of this locution in a moment. This same problem was later illustrated by YANG Hui in his Detailed Explanations of the Nine Chapters of Computational Procedures (1261) (reprinted in (Guo 1993, vol. 1: 977)):

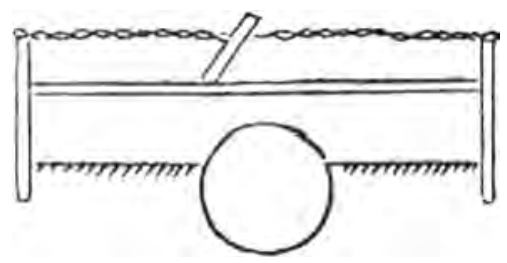

A little less than 500 years later, LIU Hui in his commentary on the Nine Chapters treats virtually the same problem as the log-in-the-ground problem from the Shu. Problem 9.09 in Chapter 9 dealing with gougu or right triangle problems in the Nine Chapters reads as follows (see at the bottom of the page).

The first difference to be noted here is that instead of the indefinite 即曰 ji yue (it says), the Nine Chapters version of the log problem now specifies the procedure to be followed as 术曰 shu yue (the method says). The dimensions of the two problems are exactly the same, and the procedure specified leads to exactly the same answer for the diameter of the circle as 26 cun, but in the case of the Nine Chapters, there is no discrepancy between the problem asking for the circumference and the answer giving the diameter of the circle. However, in neither the Shu nor the basic text of the Nine Chapters is there any explanation of the rationale upon which the solution depends. And unless one knows the conceptual framework on which the problem is based, the procedure described seems arbitrary and hardly makes any sense.

The significant, major difference when reading this problem in Chapter 9 of the Nine Chapters is that the Nine Chapters includes the explanatory commentary by Liu Hui:

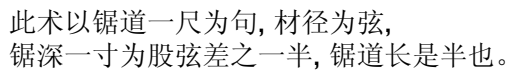

[Liu Hui Comments]: This [method] uses the length of the cut of $1 \mathrm{chi}$ as the gou, and the diameter of the timber as the xian; the depth of the cut of 1 cun is one-half the difference between the gu and xian, and the length of the cut should also be halved.

On first reading, this may not seem very helpful in revealing the conceptual framework within which this problem is cast, but at least it provides a clue as to what the mathematician was thinking in his approach to the problem: namely, this is a problem that deals in right triangle relations and, in fact, with the gou $a$, the xian $c$, and the difference between the gu $b$ and xian, i.e. $c-b$. But why does LIU Hui comment that "the depth of the cut of 1 cun is one-half the difference between the gu and xian"?

This is all made much clearer with reference to a more famous problem in the Nine Chapters whose solution is virtually the same as that for the log-in-theground/wall problem, namely Problem 9.06 devoted to the reed-in-a-pond. Here is how the problem is formulated in the Nine Chapters (see top of p. 31).

Note that here, the dimensions of the length of the side of the pond 1 zhang, and the height of the reed above the water is $1 \mathrm{chi}$. These are the same dimensions by a factor of ten as the ones that appear in the log-in-the-ground/wall problem, where the length of the cut is 1 chi and the depth of the cut is 1 cun; forget the dimensions, and the numbers are exactly the same, since 1 zhang $=10 \mathrm{chi}$; $\mathrm{chi}=10 \mathrm{cun}$.

LIU Hui also gives another clue as to what is behind the solutions to both the reed-in-the-pond and log-in-the-ground/wall problems. But to understand why, in order to solve the problem of the reed-in-thepond, LIU Hui says to multiply the 句 gou by itself and

\footnotetext{
今有圆材埋在壁中, 不知大小。以锯锯之, 深一寸, 锯道长一尺。问: 径几何?

荅曰: 材径二尺六寸。

术曰: 半锯道自乘, 此术以锯道一尺为句, 材径为弦, 锯深一寸为股弦差之一半, 锯道长是半也。
}

Suppose there is a circular [piece of] wood imbedded in a wall, whose dimensions are unknown. If a saw cuts to a depth of 1 cun, the length of the cut is 1 chi long. The question: What is the diameter [of the piece of wood]?

The answer says: The diameter of the timber is 2 chi 6 cun.

The method says: Multiply half of the length of the cut by itself, divide by the depth of 1 cun; adding the depth of 1 cun gives the diameter of the timber. 
今有池方一丈, 臀生其中央, 出水一尺。引臀赴岸, 适与岸齐。问: 水深, 葭长各几何?

荅曰:水深一丈二尺, 臀长一丈三尺。

Suppose there is a [square] pond with a side of 1 zhang, in the middle of which a reed grows, extending 1 chi above the water. If the reed is pulled to the edge [of the pond], then it just reaches the edge. The question is: How much are both the depth of the water and the length of the reed?

The answer says: The depth of the water is 1 zhang 2 chi.

The length of the reed is 1 zhang 3 chi.

The method says: Multiply half the side of the pond by itself.

[LIU Hui comments]: This [method] uses half the side of the pond, which gives 5 chi as the gou, the depth of the water serves as the $g u$, and the length of the reed is the xian. Using the gou and xian to find the gu, therefore let the gou be multiplied by itself and first find the area of the gnomon ((Dauben, Guo, and Xu 2013: 1055-1057); the illustration below is from (Yang Hui 1261), reprinted in (Guo 1993, vol. 1: 975)):

\section{圆水出臀 圆岸赴薮引}

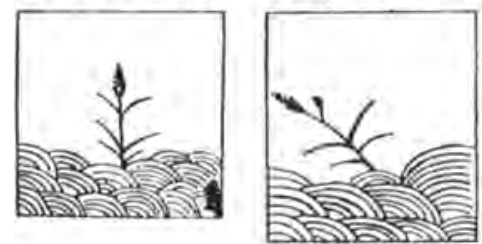

(1)（探自㛫知本）

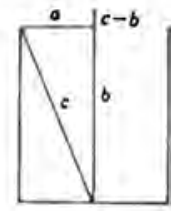

(2) then find the area of the gnomon-what gnomon?-it is necessary to explore the most basic method applied repeatedly in ancient Chinese mathematics to solve gou-gu type problems. This is related in turn to a means by which the gou-gu (Pythagorean theorem) relation itself can be proved, namely for gou $a, g u b$, and xian $c, a^{2}+b^{2}=c^{2}$.

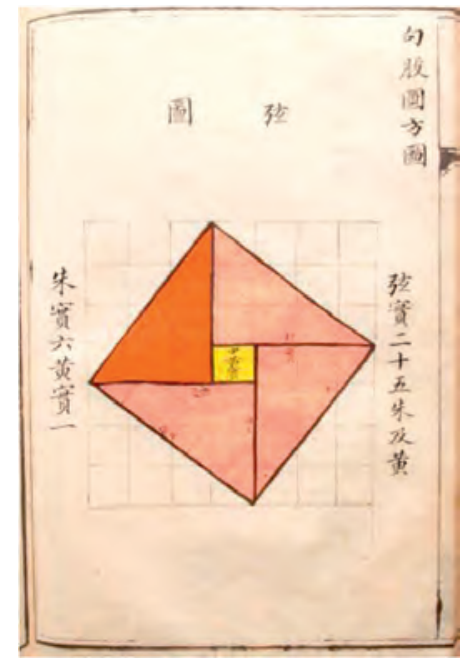

The "Hypotenuse Diagram" from a copy of the

Zhou bi suan jing, Asian Studies Library, University of British Columbia.

\section{The Ancient Chinese Out-In Principle}

The out-in principle is a fundamental method of ancient Chinese mathematics. Consider the following diagram: under what conditions may the two appar- ently different areas, one vermillion $X$ on the left, the other blue-green $Y$ on the right, be said to be equal?

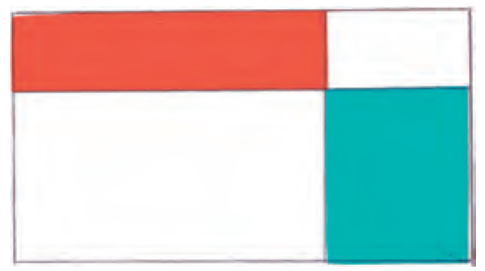

A straightforward argument shows that the two areas, vermillion and blue-green, are equal when the point at which their lower-right and upper-left corners coincide with the diagonal of the rectangle drawn through their point of mutual intersection:

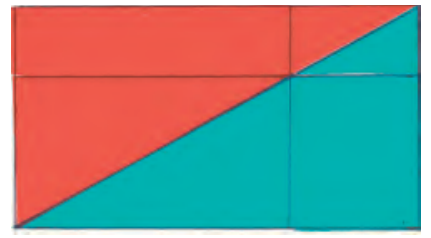

This may now be proved by a direct application of several logical principles, stated in Euclid's Elements of Geometry as axioms, but not explicitly stated as such in ancient Chinese mathematics, namely that equals subtracted from equals are equal. In the case of the above diagram, the diagonal divides the rectangle into two equal right triangles, vermillion $V$ on top, blue-green $B G$ below, i.e. $V=B G$.

But there are also two more sets of equal right triangles, in the lower left rectangle and upper-right rectangle defined by the horizontal and vertical lines parallel to the sides of the rectangle and delimiting the original red and blue-green rectangles. 


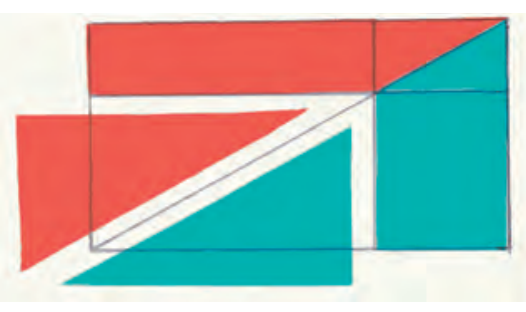

Removing these equal triangular areas from the equal triangular areas $V=B G$ immediately justifies the original proposition, i.e. thanks to the removal of equal triangular areas from two equal triangular areas, the remainders, $X$ and $Y$, must also be equal:

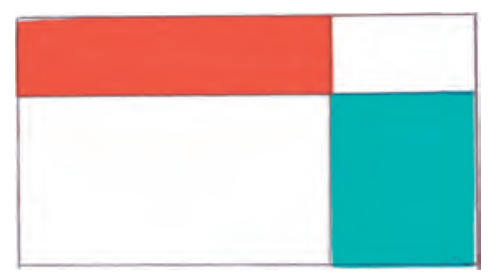

This same principle can now be applied to prove the Chinese version of the Pythagorean theorem. An argument concerning right triangles first appeared in the ancient Chinese mathematical classic, the Zhou bi suan jing, and this was accompanied with a lost diagram later reconstructed in numerous different versions, among which is the diagram depicted above, and upon which the following argument is based. Note that the diagram includes a central yellow square that is not mentioned in LIU Hui's commentary explaining the proof of the gou-gu relation. Nevertheless, the diagram is still applicable as we explain below. First, consider one of the triangles created by drawing the diagonal of a rectangle, the shorter width is the gou side; the square on the gou side is colored in vermillion. Likewise, the longer side of the rectangle is the gu side of the triangle, and the square on this side is colored in blue-green.

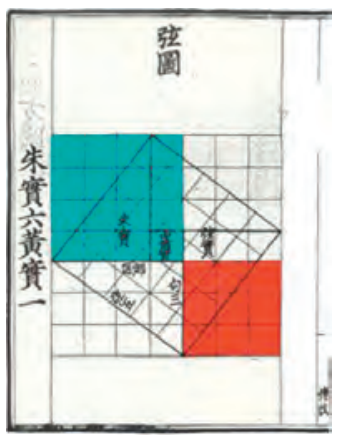

Note that the vermillion and blue-green squares overlap in part with the square drawn on the diagonal of the rectangle that also serves as the hypotenuse of the right triangle. If the colored areas of the gou

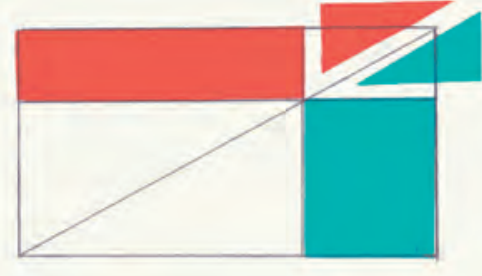

and $g u$ squares that overlap the square on the diagonal/hypotenuse are now considered "in," then the parts of the red and blue-green squares that lie outside the xian square on the hypotenuse may be considered "out," as below:

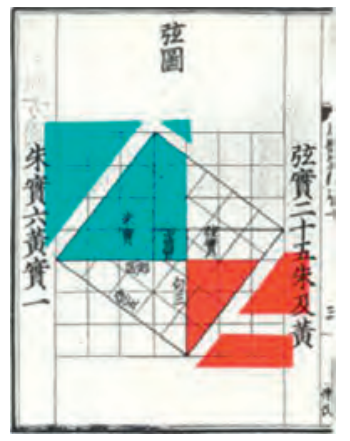

In the spirit of the out-in principle, these areas that are "out" may be moved to areas inside the xian square, so that as LIU Hui often says, "the excess fills the void." This rearrangement now transforms the former two squares on the gou and gu sides of the right triangle into the one square on the xian square, whereby LIU Hui explains the proof that $a^{2}+b^{2}=c^{2}$ by subtracting equal areas from the "outside" and adding the same areas to the "inside," thereby constituting the area on the hypotenuse as in the right-most figure (see top of p. 33).

Whereas the Chinese proof of the gou-gu theorem is different in many respects from the approach taken in Euclid's Elements, which as proven in Euclid I.47 is clearly distinctive, and also depends upon equivalences of areas but not requiring their rearrangement, both the Chinese and Pythagorean results share a common origin in the practical experience of land surveyors. In this they draw upon the same tradition as Egyptian land surveyors who used knotted ropes to measure tracts of land. With this in mind, it is surely no coincidence that both the Greek $\tau \varepsilon v o v \sigma \alpha$ (tenousa) for hypotenuse-meaning a string or cord stretched between two points-is the same idea reflected in the Chinese word for hypotenuse, xian, which means a lute string.

But how does all this help in understanding the solutions to the log-in-the-ground/wall and reed-inthe-pond problems? LIU Hui explains that both may be solved by the gou-gu method. We begin with the ex- 

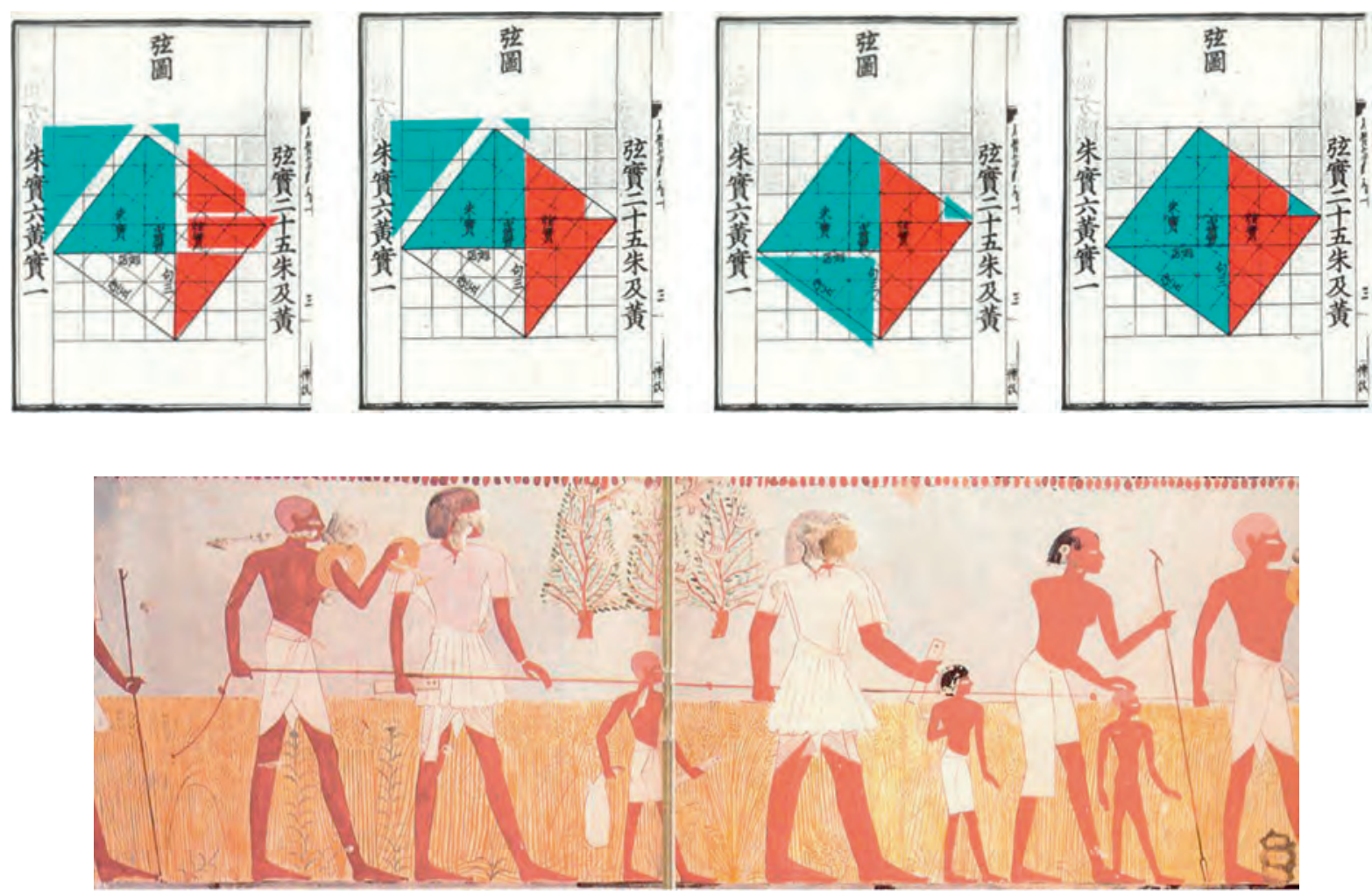

Egyptian harpedonaptai, rope stretchers, as depicted in the tomb of Menna, Sheikh abd el Qurna, New York: Metropolitan Museum of Art, 30.4.44.

ample of the reed-in-the-pond problem, and translate the various parts of the problem into the language of the diagram with colored squares representing various parts of the problem as in the figure on the right, below:

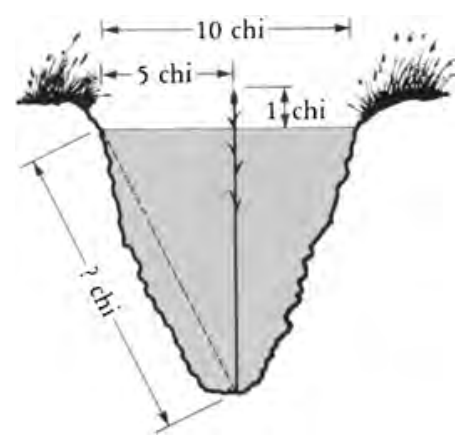

(b) (c-b)

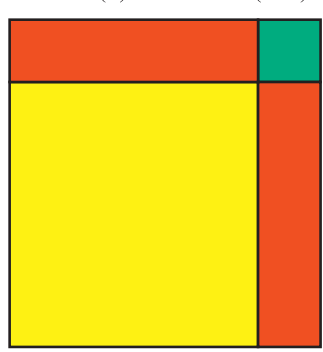

Here we translate the given data for the problem in terms of the colored diagram on the right with reference to the triangle in the diagram on the left. The shorter width of the triangle is half the width of the pond, i.e. the gou of 5 chi; the hypotenuse is the length of the reed $c$ when pulled to the side of the pond; and the $g u$ or longer length of the triangle is the length of the reed from its base to where it touches the water, $b$. The 1 chi distance of the reed above the water is also the difference between the total length of the reed or hypotenuse, $c$, and the gu side of the triangle $b$, i.e. $(c-b)$.

In terms of the diagram on the right, the length and/or width of the entire square represents the hypotenuse or length of the reed $c$, i.e. $(b+(c-b))$; the side of the yellow square is the length of the reed $b$ from its base to where it touches the water; and the 1 chi distance of the reed above the water is the difference $(c-b)$.

The crux of the argument whereby the length of the reed below water $b$ is determined depends upon the fact that $c^{2}-b^{2}=a^{2}$, and thus the area of $a^{2}$ is equal to the gnomon around the yellow square, i.e. the sum of the two vermillion rectangles and the blue-green square. This means that half the width of the pond, 5 chi, when squared is the area of the gnomon, $25 c h i^{2}$. The relationships can be written as $\left(5^{2}\right)=2(c-b)(b)+(c-b)^{2}$. Since $(c-b)$ in this case is 1 chi, this explains why the solution of the problem calls first for squaring half the width of the pond, i.e. $(5)^{2}$, from which the height of the reed above the water is then squared and the result subtracted from the $25 c h i^{2}$, i.e. $25-(c-b)^{2}=25-1=24 c h i^{2}$. This amount is now divided by twice the length of the reed above the water, 2(c-b), i.e. 2 chi, gives the answer of 12 chi for the length of the reed below the water, the length $b$, and then $b+1=13$ chi gives the total length of the reed. 
Text of the Nine Chapters.

The Method: Multiply half the side of the pond by itself, and subtract the 1 chi [that the reed] extends above the water multiplied by itself.

Dividing the remainder by the double [of the part of the reed] that extends above the water, this gives the depth of the water. Adding the amount [of the reed] that extends above the water gives the length of the reed (Dauben, Guo, and Xu 2013: 1055-1057).

Now it is clear why LIU Hui in his commentary on this problem says to begin by finding the area of the gnomon, the gnomon being the area of the gou square in terms of the given terms of the problem, the known half-width of the pond and the difference between the length of the reed and the length of the reed below water, i.e. $(c-b)$. Thus $a^{2}=2(c-b)(b)+(c-b)^{2}$.

Note too that the method as given in the original text and as interpreted by LIU Hui is completely general, even though it is verbalized in the text in terms of the numbers given in the problem. In both cases the divisions and additions of 1 are called for in the text because $(c-b)$ happens to be 1 ; nevertheless this is referred to generally, couched in terms of the amount the reed "extends above the water multiplied by itself," i.e. $(c-b)^{2}$, which LIU Hui refers to not in terms of its numerical value in the problem, but as "the difference [between the xian and the $g u(c-b)$ ] is the width of the area of the gnomon" (see at the top of the page).

This now translates directly into our understanding of how ancient Chinese mathe-maticians thought about the log-in-the-ground/wall problem. The only difference is that we are dealing with a gou-gu triangle whose sides and hypotenuse are all one-half those of the right triangle that figured in the reedin-the-pond problem. But since this is the only difference-even the basic dimensions of the problems are the same-the method proceeds exactly as in the case of the reed-in-the-pond problem.

To find the diameter of the circle $c$, the method begins as before by squaring the gou, which is half the length of the cut, i.e. $a / 2$. Interpreted in terms of the gnomon representing $(a / 2)^{2}$ : since $(a / 2)^{2}=\left(a^{2}\right) / 4=$ $2(1 / 4)(c-b)(b)+(1 / 4)(c-b)^{2}$, the next step in the
[Liu Hui comments:]

The extension [of the reed] above the water is the difference between $g u$ and xian. Subtract this "difference" area from the area of the gnomon, and then divide.

[Liu Hui comments:] The difference [between the xian and the $g u$ l is the width of the area of the gnomon, the depth of the water is the gu. Because this results from taking the extension [of the reed] above the water of 1 chi as its width, this is why the gnomon gives the length of the reed (Dauben, Guo, and $\mathrm{Xu}$ 2013: 1057).

method divides by the depth of the cut, $(1 / 2)(c-b)$, and after simplifying: $a^{2} / 2(c-b)$, which equals $b+1 / 2(c-b)$.
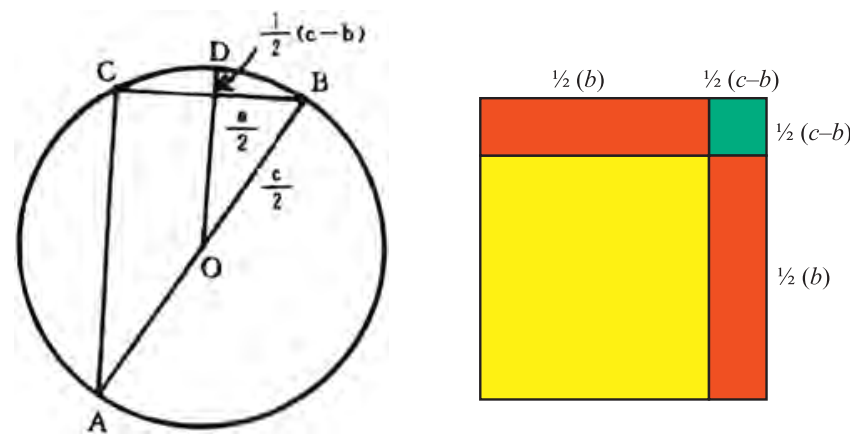

The final step, to find the diameter of the circle $c$, proceeds as the method instructs, by adding the depth of the cut: $\left[a^{2} / 2(c-b)\right]+1 / 2(c-b)=b+1 / 2(c-b)+$ $1 / 2(c-b)=c$. Thus by adding the depth of the cut, the diameter has been completed, and in complete generality, in terms of the gou and the difference between the xian and $g u$, the given terms of the problem.

\section{Extraction of Roots in the Suan shu shu Versus the Nine Chapters}

What about the mathematics in the Suan shu shu? This work dates to ca. 186 BCE, and includes a number of problems devoted to determining the areas of fields. Problem 53, given the area of a square field, asks to find the length of its side - a problem requiring the extraction of the square root. But the method may come as a surprise. It uses the method of excess and deficiency to approximate the root: if it were 15, the area would be too small; if 16, it would be too

\section{Reed-in-the-Pond}
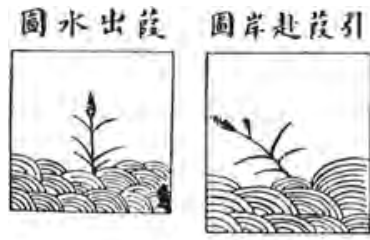

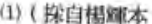

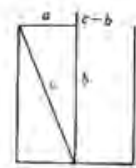

(2)
Log-in-the-Ground/Wall
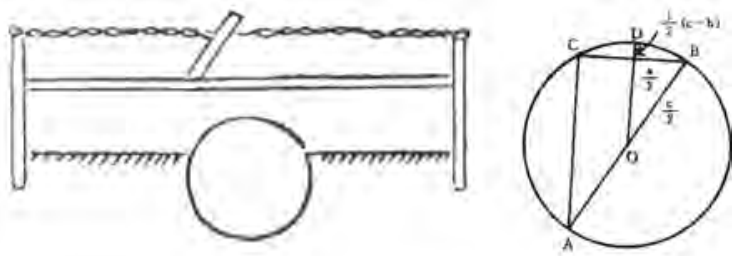


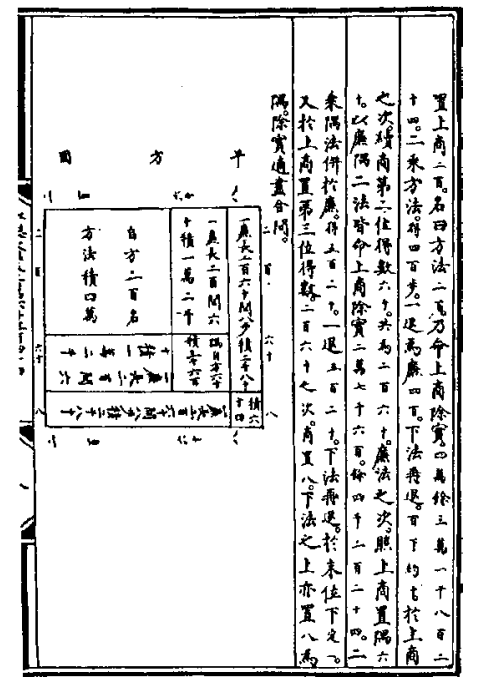

(Lam and Ang 1992: 76).

\section{JIU ZHANG SUAN SHU}

\section{Problem 4.12}

SUPPOSE THERE IS A [SQUARE] AREA OF 55,225 BU. THE QUESTION: WHAT IS THE [LENGTH OF THE] SIDE? THE ANSWER: 235 BU.

In the Nine Chapters, the method of finding square roots has been highly developed into an algorithm with its own technical designation as the 開方術 Kai fang shu or "Method of Finding the Square Root" (lit. "Method of Opening the Square" (Qian Baocong 1963, vol. 1: 150). This latter method allows determination of the square root by an iterative procedure based upon successive approximations by completing squares. large; therefore, the root must lie somewhere in between.

The same problem appears in the Nine Chapters, but with an entirely different approach to the solution of the problem. Instead of an approximation, LIU Hui in his computation of the square root presents a very precise algorithm by which the square root of any number may be extracted. The key, conceptually, is reflected in this diagram, reconstructed by the mathematician Dai Zhen for the Ming encyclopedia, Yongle dadian (1403-1408) (see at the top of the page).

Consider the number or square 55,225 ; the problem is to find the length of the side of the square. The algorithm to extract the square root begins by observing that the root must lie between 200 and 300, since $200^{2}=40,000<55,225<300^{2}=90,000$. The first step is to determine the first digit $a$ of the square root $a b c$ such that $(a b c)^{2}=55,225$. Clearly in this case the first digit $a$ of the root is 2 . Take 200 as the first approximation of the square root, and subtract $200^{2}=40,000$ from 55,225 , leaving 15,225 . In terms of the diagram, this is equivalent to removing the large yellow area 甲 jia $(40,000)$ from the larger square $(55,225)$.
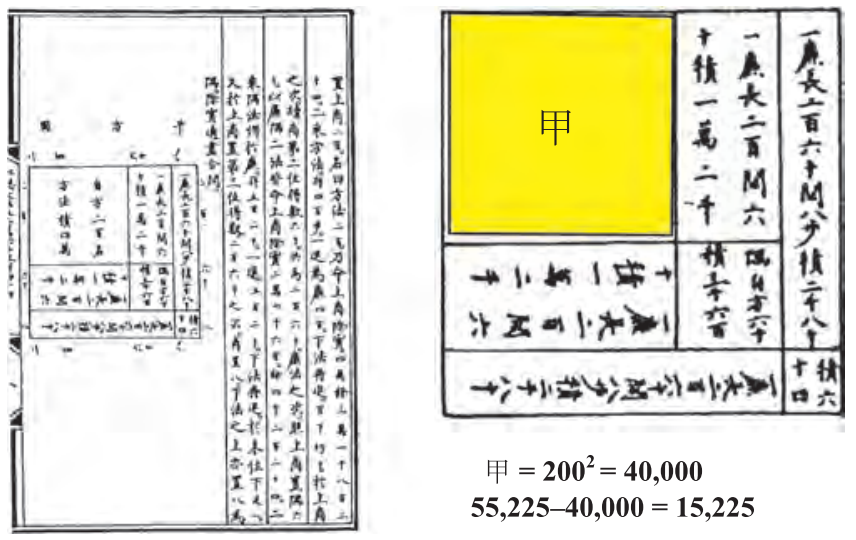

甲 $=200^{2}=40,000$

$55,225-40,000=15,225$
This leaves a gnomon of two vermillion rectangles and a smaller yellow square 乙 $y i$ between them, and then two blue-green rectangles and the even smaller yellow square 丙 bing between them. These together represent the gnomons surrounding the large yellow square, and are equal in area to $55,225-40,000=$ 15,225 .

Now, the second digit of the root is computed.
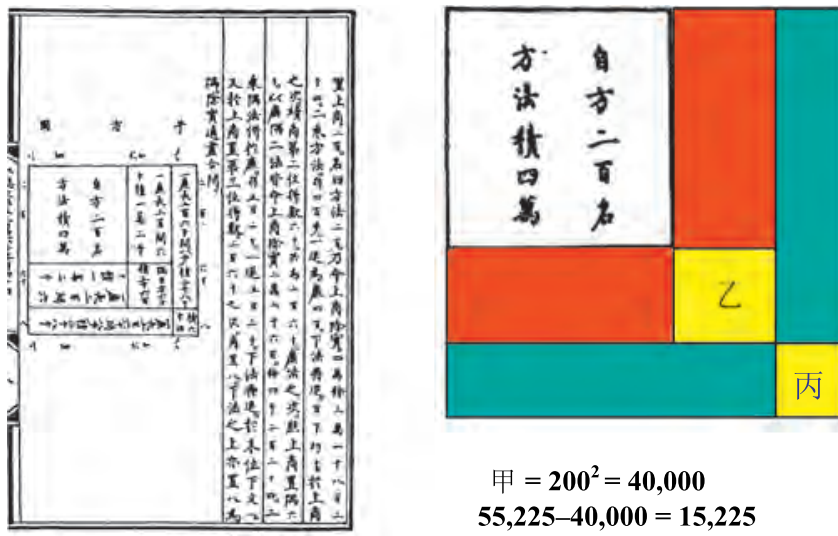

甲 $=200^{2}=40,000$

$55,225-40,000=15,225$

This time the side of the large yellow area already determines the lengths of the two red rectangles, each is 200 , and the next step in the algorithm is to estimate the next digit $b$ of the square root $a b c$ such that $2(10 b)(200)+(10 b)^{2} \leq 15,225$. Since $2(40)(200)+(40)^{2}=17,600>15,225$, and $2(30)(200)+$ $(30)^{2}=12,900<15,225$ the second digit of the root is 3 , and subtracting 12,900 from 15,225 leaves 2325, the area of the remaining outer gnomon comprised of the two blue-green rectangles and the smallest yellow square 丙 bing between them.

The final step of the algorithm is to determine the last digit $c$ of the root $a b c$. Again, the lengths of the two blue-green rectangles are predetermined by the length of either of the two vermillion rectangles and 
the side of the yellow 乙 yi square between them, i.e. 230 . Thus the problem now is to determine the final digit $c$ of the square root such that $2(230) c+c^{2} \leq 2325$. It turns out that if $c=5$, the areas of the two bluegreen rectangles will be $2(230)(5)=2300$, and $c^{2}=25$, i.e. together they total 2325 , which means that the square root of 55,225 has been determined to be exactly 235 .

This algorithm which gives a method for finding square roots in complete generality, to whatever degree of accuracy one may wish, is an obvious advance over the excess/deficiency method of the Suan shu shu. From working within the framework of a bestestimate, the Nine Chapters has literally opened the square, and by analyzing the rationale behind the method of finding the square root, has utilized a level of theoretical understanding that allows the power of the algorithm to proceed step by step to determine the square root either exactly, or as closely as one may wish.

\section{Three Multi-Tasking Problems: Traps for the Unwary Student}

\section{Fu tan, Lu tang and Yu shi}

These three problems have a number of common characteristics, not all of which are immediately obvious as one reads their texts for the first time. But they all follow one another consecutively in the Suan shu shu as Problems 46, 47, and 48, and thus the fact that they may somehow be related should come as no surprise. The most obscurely stated of the three problems is $F u$ tan, and so we begin with this, allowing the two subsequent problems to suggest how in fact its interpretation might best be approached. There is considerable disagreement about the correct data for the $L u$ tang problem, so we shall consider that second, followed by the $Y u$ shi problem, which is a problem whose method sheds considerable light on how to approach the other two problems.

\section{[Problem 46] 負炭 Fu tan: Transporting ${ }^{a}$ Charcoal (WW 2000: 82; Peng Hao 2001: 92; ZJS 2001: 264)}

Carrying charcoal from a mountain, in 1 day it is possible to carry 7 dou of charcoal to a wagon; the next day, 1 dan of the gathered charcoal taken to the wagon is transported to a government post (官 guan). Now wishing to go to the government post, carrying charcoal from [the mountain] and transporting charcoal the long distance to the government post, the question is how much charcoal is delivered in [1] day? [The answer] says: in one day 4 dou 2/[17] sheng of charcoal [is delivered]. ${ }^{b}$ The method says: taking the 7 dou multiplied by 10 [days] gives 7 dan; and [it takes]
7 days as well to transport it to the post; i.e. take the 10 days and the 7 days and combine them as the divisor; [take 7 dan as the dividend] ${ }^{c}$; dividing gives the answer in $\mathrm{dou}^{d}{ }^{d}$

a The Chinese character 負 fu literally means "to carry," and is often used in conjunction with firewood to mean "to carry on one's back." Here it also appears with charcoal in the sense of transporting the gathered charcoal to a government post, and so in translating the title of this section of the Suan $s h u s h u$, the more inclusive sense of fu is rendered here.

$b$ The answer in the text is mistakenly given as 4 dou 2/11 sheng, but is corrected here as 4 dou 2/17 sheng.

${ }^{c}$ Although the problem fails to say so explicitly, it is clear that the method requires that the 7 dan, or more precisely its equivalent amount in dou, serves as the dividend for the solution of this problem.

${ }^{d}$ Hao PENG is the only commentator to note that it is necessary to specify the dividend, and he supplies the part in parentheses here as missing but needed to complete the method in conformity with the preceding statement of the problem (Peng Hao 2001: 93, note 4). Arguably, it would be easier to indicate the dividend earlier in the sentence by inserting only two characters after “...gives 7 dan (爲實 wei $s h i=$ as the dividend)," but the end of the method is still missing a character which PENG Hao also supplies, the "shi" for the final formulaic instruction 實如法得一斗 shi ru fa de yi dou (dividing gives the answer in $d o u$ ).

On first reading, it is not immediately apparent exactly what this problem may involve, and indeed, the Tongxun group in commenting on this problem notes that, with regard to the second sentence in particular, "the meaning of this sentence is not clear," (Tongxun 2000: 14, note 137 to Problem 46). What all of the commentaries do agree upon is that the fraction given as part of the answer in the original bamboo text is wrong and should be corrected to $2 / 17$ sheng. Before trying to interpret this problem further, however, it will be helpful to examine first the two following problems (which, as it turns out, are closely related in terms of their method of solution).

\section{[Problem 47] 盧 唐 Lu tang: Bamboo Ladles/Utensils ${ }^{a}$}

(WW 2000: 82; Peng Hao 2001: 94; ZJS 2001: 265)

The norm says: in 1 day 60 stalks of bamboo are cut down; in 1 day [it is possible to make] 15 lu tang, one stalk of bamboo equals 3 lu tang. If 1 person is told to cut down bamboo himself to make lu tang, how many can be made in 1 day?

[The answer] says: 13 and 3/4 lu tang.

The method says: take 60 as the divisor, and take 55 times 15 as the dividend.

a A lu tang was some sort of cooking or serving utensil made of bamboo, perhaps a ladle or large spoon. See (Peng Hao 2001: 94, note 1).

There is no agreement about the answer or the method of calculation for this problem. The Tongxun 
group says that there are problems in reconciling the method of calculation with the answer, not to mention "that there is no particular explanation for any of the numbers in this method," (Tongxun 2000: 14, note 141 to Problem 47). (The method as stated in the original problem calls for the following calculation: $(55 \times 15) / 60=133 / 4$ lu tang. $)$

Shirong GUO offers a number of changes to the above text, which he reads in two different ways, concluding that it must be a conflation of two different problems. In one version, he accepts the given data but then changes the method which results in a different answer: $(60 \times 15) / 65=1311 / 13$ lu tang. But he also hypothesizes a second version of the problem, which he bases on the given answer, but which requires a different set of original given data, such that the method then calls for the following computation: $(55 \times 15) / 60=133 / 4$ lu tang. He concludes that the version of the problem that survives in the Suan shu shu is a conflation of these two problems, taking the data of the former but then using the method and answer of the latter. His argument includes a reconstruction of the two problems as he believes they must have been given prior to the mixed-up version of the Suan shu shu (Guo Shirong 2001: 282, annotation to his Problem 34, "Lu tang").

Shuchun GUO basically agrees with Shirong GUO's treatment of this problem, except that he does not opt for the hypothetical complication of there having been originally two different problems, but instead revises the text as if the first of Shirong GUO's interpretations were correct. Thus he considerably revises the given text, including the answer, which he corrects to 13 11/13 lu tang (Guo Shuchun 2001: 213, notes 1, 2, and 3 to "Lu tang").

Hao PENG, on the other hand, believes the text should be corrected in a slightly different manner, on the assumption that the method should be the same as that for the preceding "Fu Tan" problem. Thus Hao PENG accepts the data, but not the method as given in the Suan shu shu, and argues that the correct computation and answer should be: $(60 \times 15) /(60+15)$, with the result that exactly 12 lu tang can be made by one person in one day (Peng Hao 2001: 94, note 5). The reading of the problem in (ZJS 2001: 265) is virtually the same as Hao PENG's, and makes the same corrections to the original text, but with no interpretation of the problem nor details of how the calculation itself should be worked out.

The extent of the disagreement about the data given in this problem and its correct solution is quite surprising, because if one carefully works through the problem, counting the parts of a day it takes to cut down one stalk of bamboo and make three $l u$ tang from each stalk, the answer comes out exactly as the problem says it should, to a total of $133 / 4$ lu tang that one person working alone can make in one day.

So why should there be any disagreement at all about this problem? While it may be true that the rationale for the method and numbers as stated in the problem, namely $(55 \times 15) / 60=133 / 4$ lu tang, is not immediately obvious, rather than changing the data, if everything actually works as stated in the problem, it would be preferable to try to ascertain the reasoning that the mathematician who formulated this particular problem may originally have had in mind.

Before trying to determine what logic may serve to explain the method for the "Lu tang" problem as given in the Suan shu shu, on what grounds can we be sure that the data are indeed correct, and that in particular, the answer should not be $1311 / 13$ or simply 12? In fact, this problem does have a straightforward solution, but not one that is immediately apparent from the stated method, nor does the method at first seem to bear any obvious connection to the problem itself, except for the fact that it gives the correct answer. But first, given the fact that all of the previous commentators on this problem have either questioned the data or given very different answers from that given in the original problem, how can we be sure that the given answer is correct? The basic reasoning of the problem is as follows:

If in one day it is possible to cut 60 stalks of bam-
boo, it takes $1 / 60$ of a day to cut down 1 . Simi-
larly, it takes $1 / 15$ of a day to make one lu tang.
Since 3 lu tang can be made from 1 stalk of bam-
boo, it will take $13 / 60$ of a day to cut down 1 stalk
of bamboo $(1 / 60)$ and make 3 lu tang $(3 \cdot(1 / 15))$,
i.e. $(1 / 60+3 / 15)=13 / 60$. In four such units of time
(52/60), it is possible to cut down 4 stalks of bam-
boo and make 12 lu tang. This leaves $8 / 60$ of the
day; cutting down one more stalk of bamboo takes
$1 / 60$, leaving $7 / 60$ of a day. It takes $1 / 15=4 / 60$ of
a day to make 1 lu tang, which brings the total of
lu tang for the day to 13 , with $3 / 60$ of the day left.
But since it takes $4 / 60$ of a day to make a complete
lu tang, it is only possible to complete $3 / 4$ of one,
for a total of lu tang made in one day of $133 / 4$.

Consequently, there is no reason to change the data of the problem, and no reason to consider it as a conflation of two distinct problems that have been improperly merged into one problem with a set of conditions inconsistent with the answer given. The data and answer are perfectly consistent, although there is still the question of the method; where does the solution procedure for this problem as given in the Suan shu shu come from? Before it is possible to give a satisfactory answer to this problem, it will help to examine the problem, method and solution for the last of our trio of problems, all involving "shared tasks." This is Problem 48 of the Suan shu shu devoted to "Feathering Arrows." 
[Problem 48] 羽矢 Yu shi: Feathering Arrows

(WW 2000: 82; Peng Hao 2001: 95; ZJS 2001: 265)

The norm: one person in one day makes 30 arrows or 20 feathered arrows. If one now wishes to have one person both make arrows and feather them, in 1 day how many can be made?

The answer: 12 .

The method: combine the arrows and the feathering as divisor; taking the arrows and the feathering, mutually multiply them together as the dividend.

This is the most transparent and the easiest to understand of these three related problems. There is virtually no disagreement about how it should be interpreted, or how its method produces the desired result. Except for explaining that 羽矢 $y u$ shi (feathering arrows) refers to the process whereby feathers are attached at the end of an arrow's shaft, which according to the problem itself takes $1 / 20$ of a day, the Tongxun group only gives the working of the method, which from the above statement of the method can be seen to result in the following calculation: $(30 \times 20) /(30+$ $20)=12$ (Tongxun 2000: 14, note 143 to Problem 48). Neither Shirong GUO nor Shuchun GUO offers any comment on this problem. Hao PENG gives a step-bystep working out of the problem (Peng Hao 2001: 95, note 2). Aside from a very brief note explaining what "yu shi" means, (ZJS 2001: 265) offers no further commentary on Problem 43.

The problem and its method may be understood as follows. If it is possible to make 30 arrows in one day, or to feather 20 arrows in one day, it will take $1 / 30+1 / 20$ of a day, or $5 / 60$ of a day to make one arrow and then to feather it. Accordingly, in one day, it is possible to make $1 /(1 / 30+1 / 20)=(30 \times 20) /(30+$ 20 ) feathered arrows, or a total of 12 . This is exactly the method described in the problem, and exactly what the answer says should be expected as the answer.

But why does the application of this method fail in the case of Problem 47? Hao PENG says that all three of these problems may be solved by the same method (Peng Hao 2001: 93, note 5 to "Fu tan"), but this is not exactly the case. If the method were the same, then the "Lu tang" (Bamboo Ladles) problem should indeed follow from a similar formula, as Hao PENG suggests: $(60 \times 15) /(60+15)=12$, but we know this is the wrong answer. To resolve this discrepancy, Hao PENG simply changes the answer to the problem, and lets it go at that, but this is hardly satisfactory. Knowing that the correct answer is in fact $133 / 4 \mathrm{lu}$ tang, what has gone wrong in Hao PENG's interpretation of the problem? The difficulty is that Problem 47 is not strictly an either/or problem. It is not just cutting down 60 bamboo poles in an hour, or making
15 lu tang in an hour, but these two tasks are interrelated.

We have already worked through the logic of the problem to be satisfied that the data and answer are correct. But where does the procedure of the method come from? We know from the statement of the problem itself that the given solution prescribes the following calculation: $(55 \times 15) / 60=133 / 4$ lu tang/day. We can see here the 60 bamboo poles that one can cut down per day, and the 15 lu tang that one can make in one day, but where does the 55 come from? What possible significance could this have in the context of Problem 47? Here I am indebted to Yibao XU for the following suggestion, which is a very clever answer to this question. His argument is as follows: in one day it is possible to make at most 15 lu tang, which would in turn require 5 bamboo poles; thus it would take 5/60 of a day to cut down the necessary bamboo poles. If one has spent $5 / 60$ of the day in cutting down 5 bamboo poles, this will leave 55/60 of the day in which to make lu tang. In an entire day, it would take $60 / 60$ of the day to make 15 lu tang, but we now have only $55 / 60$ of the day left; and in this time we can make $(55 / 60)(15)=(55 \times 15) / 60=133 / 4$ lu tang/day, exactly as Problem 47 gives in the Suan shu shu for both the method and the answer to this problem.

If this now makes sense of the "Lu tang" problem, with all of the above experience at our disposal, it will be an easy matter to return to the first of the problems we considered here, and resolve Problem 46 in the Suan shu shu, "Fu tan" (Transporting Charcoal). Recall that here again we have a task-sharing problem, that there are two distinct activities, and the only question we have to resolve is whether the two tasks involved in Problem 46 are independent of each other as in Problem 48, Yu shi (Feathering Arrows), or dependent upon each other as in Problem 47, Lu tang (Bamboo Ladles)?

Recall that the Tongxun group, although it says that the statement of the "Transporting Charcoal" problem is not clear, notes that according to the method of the problem, the number originally given in the answer as 11 should be changed to 17 , and that from the statement of the method itself, the correct calculation of the problem should proceed as follows: $(7 \mathrm{dou} \times 10) /(7$ days +10 days $)=42 / 17$ dou/day . But the group offers no interpretation as to how this problem should be understood (Tongxun 2000: 14, notes 136-139). Shurong GUO, in his commentary on this problem, only notes that the answer is wrong based upon the statement of the problem and the method, and makes the same correction as does the Tongxun group. He offers no further comment on the problem or how it should be interpreted (Guo Shirong 2001: 282, his Problem 33). Similarly, Shuchun GUO 
makes the same correction that Shirong GUO makes, but adds no further commentary (Guo Shuchun 2001: 213, note 1 to "Fu Tan").

Hao PENG offers the lengthiest analysis of this problem of any considered here, and explains that either it is possible to carry 7 dou of charcoal from the mountain to the waiting cart in 1 day, or it is possible to transport $1 \mathrm{dan}=10 \mathrm{dou}$ of charcoal to the government post (Peng Hao 2001: 93, note 5 to "Fu Tan"). Following the same reasoning as applied in the case of the "Yu shi" (Feathering Arrows) problem, this means that it will take $1 / 7$ of a day to carry 1 dou of charcoal to the cart; if $10 \mathrm{dou}$ can be delivered to the government post in one day, then it takes $1 / 10$ of a day to deliver 1 dou (we ignore the obvious inefficiency of all this). Thus, doing both together as in the Feathering Arrows problem, it will take $1 / 7+1 / 10$ of a day both to gather charcoal and deliver it to the government post. In one day this means it will be possible to transport a total of $1 /(1 / 7+1 / 10)$ dou of charcoal, or $(7 \times 10) /(7+10)=70 / 17=42 / 17$ dou of charcoal in 1 day, exactly as the problem prescribes.

But we may still be puzzled by the 7 days and 10 days that feature prominently in the method given for solution of the problem. Where do these come from for a total of 17? Hao PENG explains that the amount of charcoal collected in one day of $7 \mathrm{dou}$ is increased by a factor of 10 "to facilitate the computation of that which is sought" (以求計算便捷 yi qiu jisuan bianjie) (PH 2001: 93, note 5). Thus at a rate of 7 dou/day, in 10 days 70 dou or 7 dan will be collected. Now what follows is apparent, since we know that it takes 1 day to transport 1 dan of charcoal to the government post, to take all 7 dan will take 7 days, for a total (collecting and transporting) of 17 days. Now, if each day the charcoal collected (the $70 \mathrm{dou}$ ) were transmitted to the post over this 17 day period, this would be $70 \mathrm{dou} / 17$ days, i.e. $(7 \times 10) /(7+10)=42 / 17$ dou/day.

Thus, in the final analysis, our three multi-tasking problems from the Suan shu shu all work out very nicely, and with only one error that actually needs correction, namely the 2/11 sheng in the answer of the "Fu tan" problem, which should be corrected as above to $2 / 17$. And this was most probably no mathematical error in either reasoning or computation, but simply a scribal error due to a misreading on the part of the copyist. This might easily have arisen from mistaking the character for 7 in Chinese for a 1, since the only difference between the two, 七 $q i(7)$ and $-y i$ (1), is the single downward stroke (shuwanggou) of the 7 , which had it been faint enough in the original, might easily have been overlooked, and the 1 mis-transcribed as a result. (A similar mistake actually happens in at least one other place in the Suan shu shu, in Problem 27, 税田 Shui tian (Taxing Farmland), where the number 37 is miswritten for 31 (See WW 2000: 80; Peng Hao 2001: 71; or ZJS 2001: 258). For discussion of how easily the numbers 7 and 10 were mistaken in written documents of this period, see Michael Loewe's study of texts from Mu-durbeljin, in (Loewe 1967: 105)).

The three multi-tasking problems in the Suan shu $s h u$, taken together, teach valuable lessons for mathematicians of any age, whether in ancient China or in the $21^{\text {st }}$ century, namely that the terms of a given problem must be fully understood and appreciated before it is possible to find the correct method that will give an appropriate solution. The wrong method applied inappropriately may yield an answer, but the correct answer depends upon a proper appreciation of the data and the logic of the problem itself. In all of mathematics, wherever in the world it has been practiced, this has always been what leaves the mark of genius on mathematical invention-knowing how to devise or apply the proper method in the case of especially tricky or ingenious problems. It may well have been intentional that the "Lu tang" problem comes between two problems that use a straightforward application of the "multi-tasking" method for their solutions, in hopes of catching the unwary who might simply apply the same method without realizing that the situation in the "Lu tang" problem requires a slightly different approach.

The bamboo text of the Suan shu shu is thus one of the earliest examples we yet have of how adept ancient Chinese mathematicians were at devising not only clever problems, but equally ingenious methods for their solution, with rich and subtle variations on what would become classic problems in the history of Chinese mathematics.

\section{Archimedes and LIU Hui on Circles and Spheres}

One last example to be considered here of the remarkable achievements of ancient Chinese mathematics is the analysis LIU Hui made of the areas of circles and volumes of spheres, both of which invite comparison with the similar results of the ancient Greek mathematician Archimedes. In fact, the Archimedes part of this comparison begins with a mystery-the mystery of a long lost codex of Archimedes that resurfaced briefly at the turn of the last century, long enough for the Danish historian of mathematics Johan Ludwig Heiberg to identify, photograph and eventually transcribe "The Method" and several other works by Archimedes of considerable mathematical interest.

Heiberg was from a wealthy family. The son of a doctor, Heiberg studied classical philosophy and was 

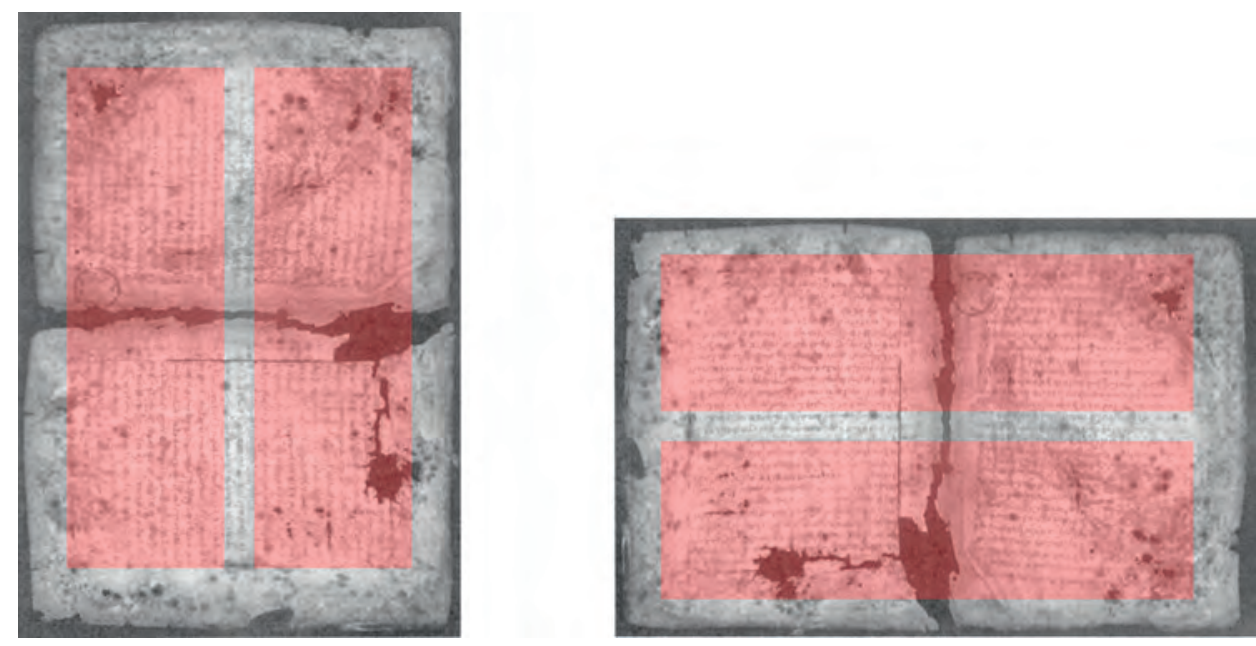

The original Archimedes codex, copied in miniscule, in two vertical columns, as illustrated on the left; the Euchologion would have been created by rotating the original folio page $90^{\circ}$ to create both a verso and recto page for the prayer book. The Archimedes text is now split horizontally, half on the left, half on the right.

professor of the subject at the University of Copenhagen. In 1879 he completed his dissertation, Quaestiones Archimedeae, devoted to Archimedes' life, works, and transmission of his texts. He subsequently published editions of Euclid's Opera (1883-1895), Apollonius' Conics (1890-1893), and the complete works of the Danish philosopher Søren Kierkegaard. But his life's greatest achievement was reconstruction of the text of Archimedes' Ephodos (The Method), discovered in Constantinople in $1906 .^{1}$

Because of his thorough knowledge of Archimedes, Heiberg was able to decipher most of the barely-legible palimpsest, aided by his good friend H. G. Zeuthen, a mathematician and historian of clas-

1 This long lost work has been almost completely obliterated, transformed into a palimpsest from which the original Archimedes text was scraped away and upon which a medieval prayer book was copied, written literally on top of the Archimedes manuscript. As for the title of the codex that interests us here-The Method-there is a problem with this usual translation that dates to Heiberg's edition of the text. Eberhard Knobloch points out that: "The underlying Greek notion for 'procedure' is 'ephodos' that is the same notion used by Archimedes in his famous letter to Eratosthenes. In both cases, 'ephodos' must not be translated by 'method'. Whenever Archimedes spoke of the method we nowadays call 'mechanical method' in this letter he used the word 'tropos'," (Knobloch 2008: 205). As C. M. Taisbak puts this, ephodos "does not mean 'Method' in the modern sense of the word, but rather 'Approach'. As it emerges from Archimedes' foreword, a title 'Entering Mechanical Problems by the Back Door' would much better cover his attitude. After all, he knew that this was heuristics, not deduction," (Taisbak 1999).

My own reading of "Ephodos," however, translates this as "attack"-its meaning in both ancient and modern Greek-not random attack but systematic, methodical, careful attack-just the sort a mathematician like Archimedes might wage upon a particularly difficult and challenging problem. sical Greek mathematics. Oddly, Heiberg wrote little on the subject from a purely mathematical point of view. His major interest was the transmission of mathematical texts-their transmission and preservation-as well as the remarkable contents of the long-lost palimpsest. The details of the rediscovery of this important work are recounted in the recent book by Reviel Netz and William Noel, The Archimedes Codex (Netz and Noel 2007).

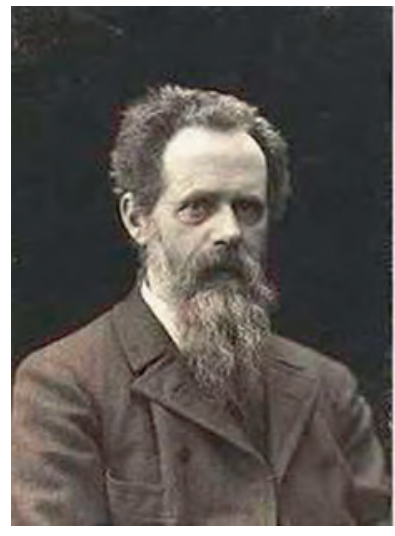

J.L. Heiberg, ca. 1887

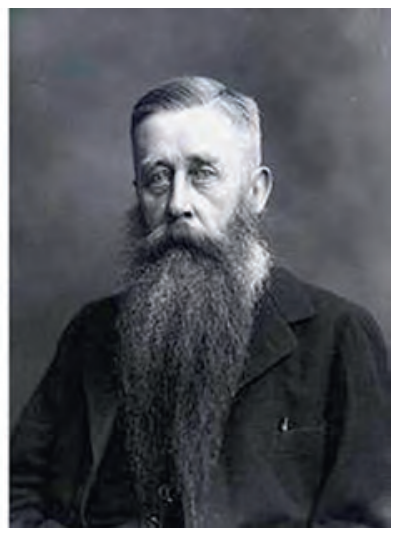

J.L. Heiberg, ca. 1906
The basic story, in very brief outline, is as follows. A Byzantine Greek copied an earlier manuscript version of the Ephodos onto parchment sometime in the $10^{\text {th }}$ century, possibly in Constantinople where Leo the Mathematician transcribed many ancient texts into minuscule. On April 14, 1229, Ioannes (John) Myronas, probably working in Jerusalem, finished the palimpsest version of a Euchologion, or prayer book, using the parchment from which the text of Archimedes had been scraped away; eventually, the prayer book was moved from Jerusalem to the Monastery of Saint Savvas, near Jerusalem. 
In the mid-nineteenth century the prayer book was transferred to the library of the Greek Patriarch in Jerusalem, the Metochion. It was at this point that the German scholar, Constantine Tischendorf (1815-1874), saw it on one of his travels to Greek monastic libraries, and he mentioned it in $1846 .{ }^{2} \mathrm{He}$ also took one sheet as a souvenir (see below)!

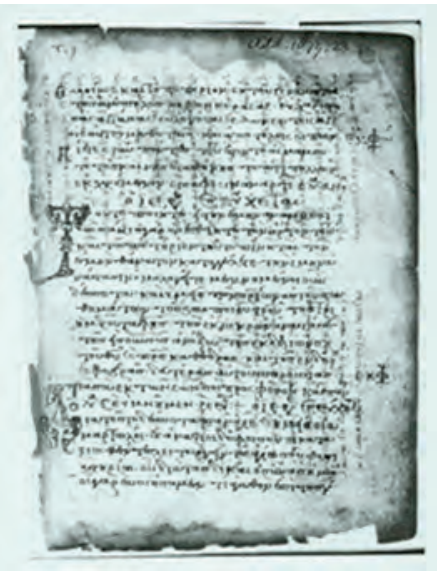

In 1876 this was sold to the Cambridge University Library, but it was only identified much later as an Archimedes manuscript page by Nigel Wilson, in 1971. ${ }^{3}$ Even before the Archimedes palimpsest was rediscovered, Tohru Sato used his analysis of this one page from the Cambridge University Library to reconstruct Propositions 14 and 18 from the Ephodos, to which we shall return momentarily (Sato 1986: 74).

It was in Jerusalem that the Greek scholar Papadopoulos Serameus catalogued and identified the palimpsest as being in part a work of Archimedes-something Tischendorf had apparently missed (in fact, in the latter part of the nineteenth century Kerameus catalogued nearly 900 manuscripts in the Metochion's collection). This is how Heiberg originally learned of the Archimedes palimpsest.

To make a palimpsest, one begins by unbinding a bound parchment manuscript, and then cuts the parchment in half down the middle, separating the formerly verso (left) and recto (right) portions of the parchment. These are then rotated ninety degrees, stacked with other divided pages of the original manuscript, and folded into folios, producing right and left pages for the new manuscript that are onefourth the size of the original parchment. Note that the top of the original codex page is now on the recto side of the new page, and the bottom half is on the verso, and the middle part of the original text is lost in the gutter of the new binding. Worse yet, when the palimpsest sheets are grouped into folios, the top

\footnotetext{
2 For more on Tischendorf, see (Black and Davidson 1981).

3 (Netz and Noel 2007: 130). The page was taken from the palimpsest between folios 2 and 3 .
}

and bottom of the original codex page may be separated by many pages of other pages stacked on top of them in comprising the folio, and the recto of a later page will run onto the verso of an earlier page of the palimpsest. Thus reconstructing the original text involves a kind of jig-saw puzzle reconfiguration.

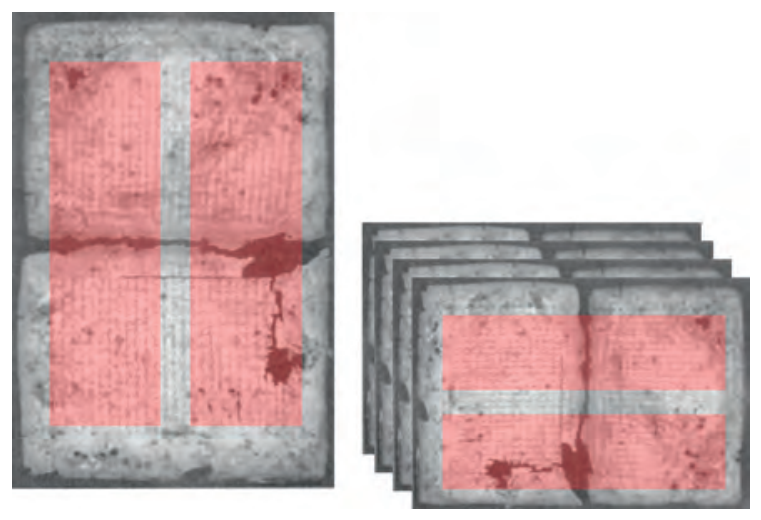

The original parchment manuscript of the Archimedes codex as copied into miniscule is represented on the left; after rotating these folio pages $90^{\circ}$, these were stacked with other leaves from the original manuscript to form the folios of the Ecologion, making a jigsaw of the original codex.

For example, over the critical Proposition 14 of the Method, the scribe wrote a prayer for the dead. But to read the entire proposition 14, it starts in column 1 of folio 110 recto of the palimpsest; you would then have to turn the codex 90 degrees to read the Archimedes text, but towards the bottom of the Archimedes text, it disappears into the gutter of the palimpsest; the Archimedes text then reappears five folios earlier, on 105 verso, but the first few lines would again be hidden by the gutter of the palimpsest, lines that Heiberg was unable to see. The next continuation of the Archimedes text appears on folio $158 .^{4}$

Comparable in some interesting ways to the Archimedes palimpsest is the oldest actual work of mathematics that currently survives from ancient China, the Suan shu shu. Hao PENG and other Chinese scholars who have studied this text simply refer to it as a Book on Arithmetic (Peng Hao 2002). But the problems it treats -68 in all on nearly 200 bamboo slips-include more than arithmetic, notably geometry, and so the title is problematic.

On the back of what is taken to be the sixth bamboo strip comprising the book are three characters, 算數書 Suan shu shu. Christopher Cullen, former Director of the Needham Research Institute for study of the history of East Asian science, technology and

\footnotetext{
${ }^{4}$ For details supplied by William Noel, see (Netz and Noel 2007: 125).
} 


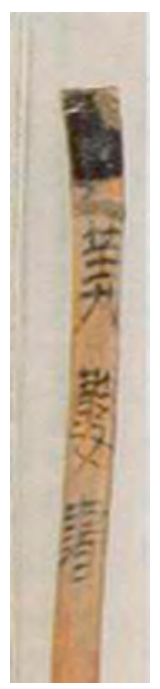

medicine in Cambridge, England, treats 算數 suan shu as one word meaning "computation," and therefore has called this a "Book on Reckoning" in his translation with commentary (Cullen 2004). But I prefer to translate each of the characters separately as "A Book on Numbers and Computation." Note the bamboo slip carries the ancient seal character for 笄 suan, but in virtually all modern editions of this work this character is rendered by the modern form of the character, 算 suan.

The Suan shu shu is the earliest yet-discovered mathematical text to survive from Chinese antiquity from a dated archaeological context. Like other documents preserved on silk, bamboo, and bronze, it constitutes an artifact from the time it was written. When archaeologists excavating the tomb of an ancient Chinese nobleman at a Western Han Dynasty site near Zhangjiashan, in Jiangling county, Hubei Province, discovered a number of books on bamboo strips in December and January of 1983-1984, these included works on legal statutes, military practice, and medicine. Among these was a previously unknown mathematical work on some 200 bamboo strips, the Suan shu shu, or Book of Numbers and Computations. Based upon other works found in the tomb, especially a copy of the Statutes of the Second Year of the Lü Reign, archaeologists have dated the tomb to ca. 186 BCE. When found in tomb 247 at Zhangjiashan, the individual bamboo strips constituting the book were found amassed together in the tomb, layered as in the figure below. The first challenge facing archaeologists after deciphering the characters on the strips, sometimes faded or illegible, was to rearrange the individual strips to reconstitute the original book itself. This was not unlike the challenge facing the conservators and editors of the Archimedes palimpsest, who also had to tackle the initial problem of reconstituting the original mathematical text of the Ephodos.

As he approached the Archimedes palimpsest, Heiberg photographed the pages from the palimpsest that interested him, mainly those corresponding to the Ephodos. More than a century later, these now serve to document how the palimpsest has deteriorated dramatically over the past century, due to careless-one might say derelict-neglect to preserve it, allowing mold to eat away at the parchment due to overly-damp conditions. The Euchologion was further compromised when its Parisian owner, in an attempt to enhance its value probably sometime in the 1940s, paid a skilled forger to paint illuminated panels over several pages that had no such ornamentation when Heiberg saw it in Istanbul at the turn of the century.

What is amazing is that Heiberg was able to read as much of the palimpsest as he did. Apart from what he could read himself, he had only the photographs and a magnifying glass to aid him. However, highresolution laser technology has made it possible to produce higher resolution composite images of the Archimedes palimpsest, making it possible to recover more information than Heiberg could make out a century earlier. Above all, the new imaging techniques have revealed the diagrams, as close to Archimedes' originals as we are likely to get, and as Reviel Netz

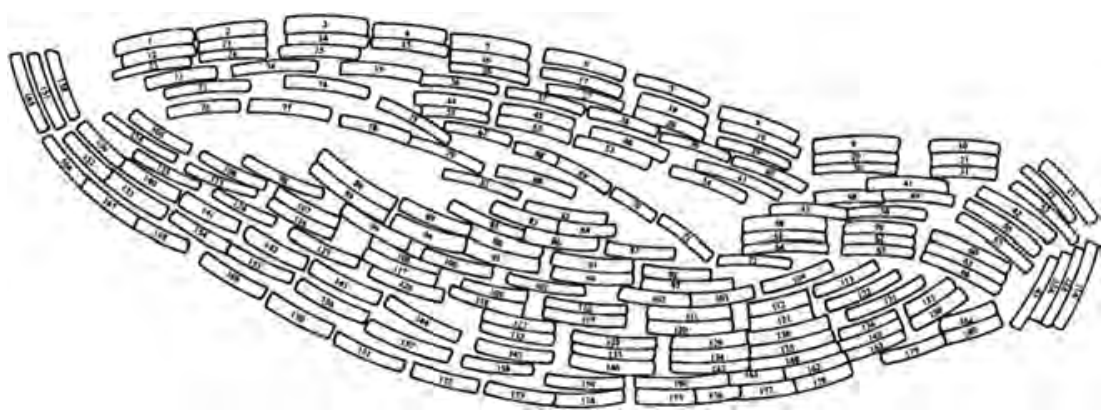

This diagram shows the relative positions of individual bamboo strips from the Suan shu shu as they were found when discovered by archaeologists excavating the tomb in which the book was found. From (Peng Hao 2002). 
argues, the mathematics for Archimedes was literally in the diagrams (see below).

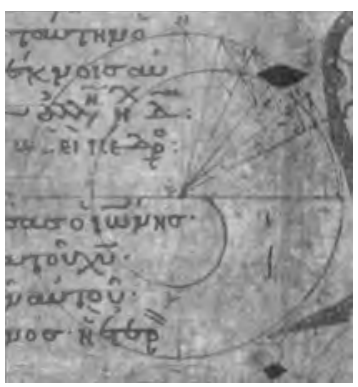

Amazingly, it appears that Heiberg paid little attention to the diagrams, which in their published version were drawn by Zeuthen. Nevertheless, according to Netz, ancient mathematicians thought in terms of diagrams, not in terms of text (Netz and Noel 2008: 132). But before turning to the actual diagrams, and Archimedean arguments concerning circles and spheres, it will be helpful to know something about what the Chinese knew of Archimedes.

Archimedes was known in China, thanks to Jesuit missionaries who used mathematics and science in hopes of persuading the educated elite of the superiority of Western Christianity. A complete translation of Archimedes' short treatise on finding the area of the circle was translated into Chinese as the 测量圈椅 Ce liang quan yi (On the Measurement of the Circle) and printed in 1635.

How did Archimedes determine the value of $p i$ or the ratio of the diameter to the circumference of a circle? A preliminary survey of the diagram of a circle of unit diameter makes it clear from the perimeter of an inscribed hexagon, whose perimeter is exactly 3 , that the hexagon falls far short of what must be a larger value for the circumference of the circumscribed circle-but exactly how much larger than 3 is the ratio of circumference to diameter? Again, even a casual inspection of a 12-sided dodecagon inscribed in the circle in place of the hexagon (as above) will provide a much better approximation of the ratio of circumference to diameter than 3.

Considering this problem from the point of view of approximating the area of the circle, Euclid proves that the area is equivalent to the area of the triangle whose height is the radius and whose base is the circumference of the circle (see diagram above left). When Euclid in Elements XII.2 determines the area of the circle in terms of its diameter, he inscribes regular polygons of increasingly-many sides to show that their areas approximate as closely as one may wish - the area of the circle. But application of this socalled method of "exhaustion" is really a misnomer, since the area is never completely exhausted.

Archimedes, in Proposition 1 of "On the Measurement of the Circle," adopts one of the most powerful arguments in the arsenal of ancient Greek mathematics-a counterfactual argument that proceeds as follows:

Let $\mathrm{ABCD}$ be the given circle, and $\mathrm{K}$ the area of the triangle of height equal to the radius and base equal to the circumference of the circle. Then, if the circle is not equal to $\mathrm{K}$, it must be either greater or less. By then appealing to both inscribed and circumscribed regular polygons, Archimedes shows that neither of these alternatives is possible, QED, the area of the circle must equal $\mathrm{K}$.
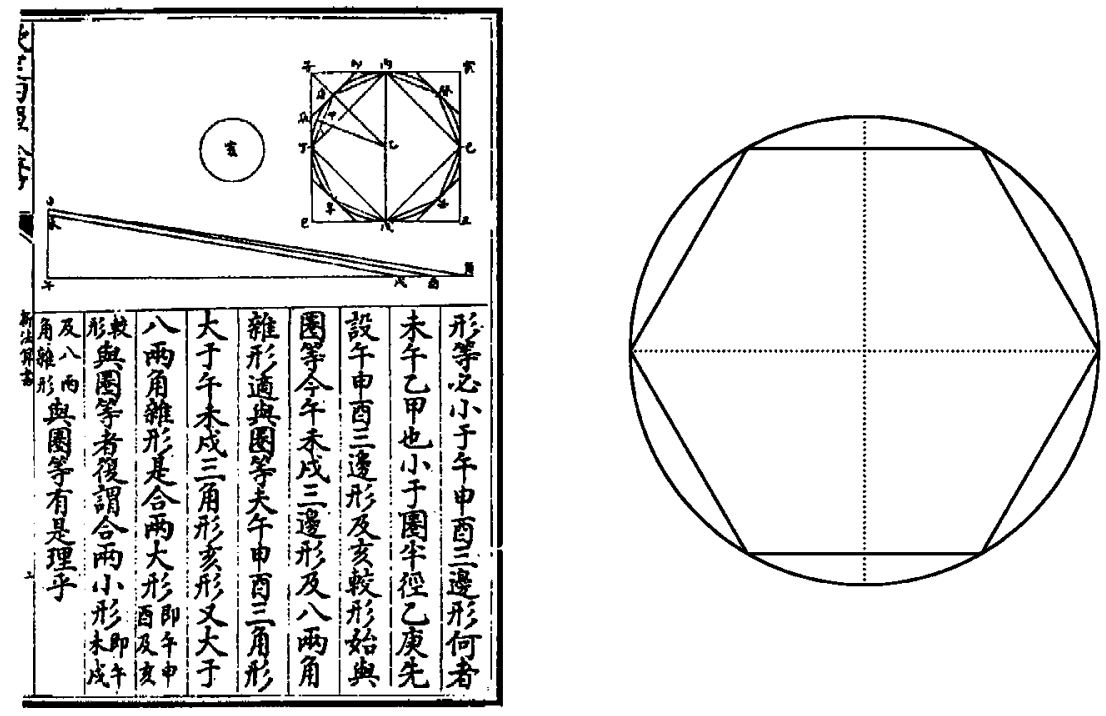

On the left is a page from the Chinese translation of Archimedes' On the Measurement of the Circle (1635); on the right, given a circle 1 unit in diameter, the radius will be $1 / 2$ unit, and the perimeter of the inscribed hexagon will be 3, clearly less than the circumference of the circle.

Thus the ratio of the diameter to the circumference of the circle must be greater than 3. 
As Geoffrey Lloyd puts it, "The Greek preference for the method of exhaustion is thus evidence both of their demand for rigour and of their avoidance of infinite processes wherever possible" (Lloyd 1996). What needs to be added is that although the Greeks did seek to avoid actually infinite processes, they were nevertheless prepared and willing to consider "potentially infinite" processes - which could stop after any arbitrary level of accuracy had been reached, the process was exhausted, or the calculator had simply grown tired of the process.

Knowing how the Greeks treated the problem of finding the area of the circle, how did ancient Chinese mathematicians approach this same problem? Here a diagram drawn according to procedures to determine the area of the circle as given in the Chinese mathematical classic, the Nine Chapters on the Art of Mathematics, through a commentary of the $3^{\text {rd }}$-century mathematician LIU Hui and reconstructed by DAI Zhen, about 1773, needs no explanation:

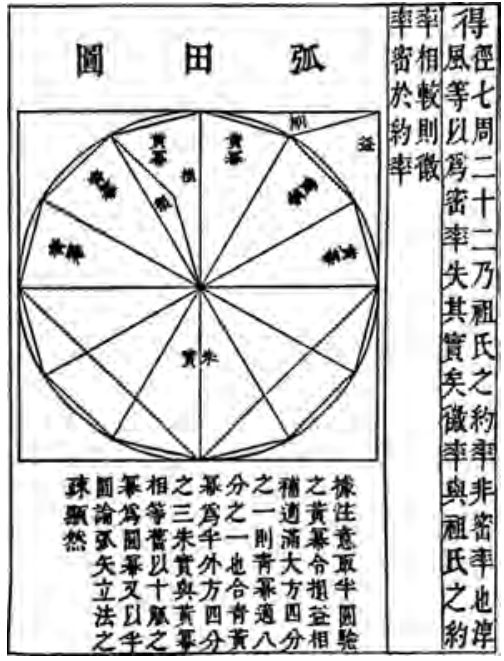

\section{DAI Zhen's diagram, as reproduced in (Needham and Wang 1959).}

Again, as for Archimedes, we don't have the original diagram and so must rely on various reconstruction (as above, by DAI Zhen), but as Reviel Netz would say, in this case the diagram literally speaks for itself and conveys the essence of the mathematical thought in question.

Note that in the Chinese diagram, however, the vertices are not lettered, but areas are identified by color-the Chinese characters in the various areas specify different colors, vermillion, yellow, and bluegreen. ${ }^{5}$ The text itself refers to terms relative to the triangles, but in Chinese there is no term for triangle;

\footnotetext{
5 For an example of how Chinese mathematicians colorcoded their diagrams in the course of their proofs, see the cover illustration of Christopher Cullen's "Learning from Liu Hui? A Different Way to Do Mathematics," (Cullen 2002). The
}

reference is only made to the colored areas, and to their sides and in the case of right triangles, their hypotenuses, respectively. Nevertheless, the gist of LIU Hui's argument as he gives it in the Nine Chapters, relies on successively finer approximations of inscribed polygons, as is immediately clear upon inspection of the diagram. From the sides of the polygons, LIU Hui can compute the area of the circle with increasing degrees of accuracy. For example, in the case of the inscribed polygon of 96 sides, his ratio of circumference to diameter of 100 is equivalent to $31464 / 624$.

However, and this should be stressed because it is an important conceptual difference between Greek and Chinese thinking on these matters, LIU Hui always speaks of the lü of the diameter and circumference, in what he calls the "precise rate," 50 and 157. He did not think in terms of a specific number like $p i$ but of a pair of numbers relating diameter and circumference. Another Chinese mathematician, LI Chunfeng, speaks of the lü of diameter to circumference as 7 and 22, and ZU Chongzhi takes the 密率 mi lü (meaning "more accurate rate") to be 113 and 355.

Returning now to the Archimedes codex, the really exciting discovery thanks to the text recovered through the applications of modern technology and computer imaging is Archimedes' Ephodos and his determination of the volume of the sphere. This is Archimedes' most famous result, established in his treatise "On the Sphere and Cylinder," wherein he shows that the volume and surface area of a sphere are $2 / 3$ of the volume and of the total surface area of a circumscribed cylinder, respectively. Archimedes considered this his greatest discovery, and the corresponding diagram, which said it all, was according to ancient accounts, engraved on his tombstone.

What is of such importance in the Ephodos is that Archimedes describes how he went about finding these results, which he outlined in a letter to Eratosthenes. In part, here is what Archimedes says:

\begin{abstract}
If in a cube a cylinder is inscribed whose bases lie in opposite squares and whose surface touches the other four planes, and if in this same cube a second cylinder is inscribed whose bases lie in two other squares and whose surfaces touch the four other planes, then the body enclosed by the surface of the cylinder and comprehended within both cylinders will be equal to $2 / 3$ of the whole cube.
\end{abstract}

He adds that he discovered this theorem by a certain "mechanical method," as he had many others of his published works. The gist of the proof is to take various plane cuts or sections that are in proportion

illustration in question is a hand-colored version of the 弦圖 xian tu (hypotenuse diagram), from a copy of the Zhou bi suan jing in the Asian Studies Library, University of British Columbia. 
to one another and show that they are in "equilibrium" or balance; knowing the result, Archimedes was then able to derive a geometric proof applying the method of exhaustion to establish the known result.

But there is one theorem in the Ephodos that is different-the geometrical derivation of Proposition 14 that so excited Reviel Netz-because a large part of this text could not be read by Heiberg. Proposition 14 establishes the volume of the sphere by examining the proportional relations between cuts of infinitesimal lamina; Proposition 15 then establishes this result rigorously using the method of exhaustion.

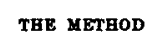

We may supply the missing proof as follows*.

In the accompanying figure are represented (1) the first

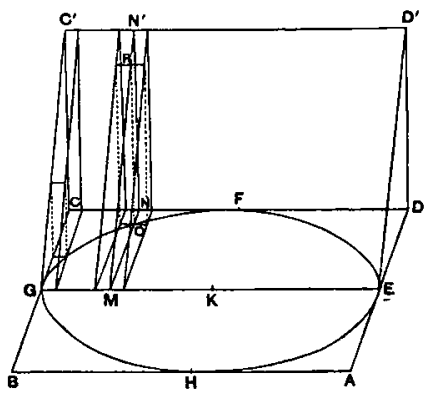

element-prism circumscribed to the portion of the cylinder, (2) two element-prisms adjacent to the ordinate OM, of which that on the left is circumscribed and that on the right (equal to the other) inscribed, (3) the corresponding elementprisms forming part of the prism cut off $\left(C C^{\prime} G E D D^{\prime}\right)$ which is $\frac{1}{2}$ of the original prism.

In the second figure are shown element-rectangles circumscribed and inscribed to the auxiliary parabola, which rectangles correspond exactly to the circumscribed and inscribed elementprisms represented in the first figure (the length of $G M$ is the same in both figures, and the breadths of the elementrectangles are the same as the heights of the element-prisna); "It is right to mention that this has already boen done by Th. Reinach in Revue generale des sciences pures et appliquees, 30 Nor. and 16 Deo. 1907) but I proter my own atatewent of the proot.

\section{The diagram for Theorem 14, as given in (Heiberg 1909).}

Archimedes was dissatisfied with his Theorem 14 , and there were probably at least two reasons for this-he did not regard results based on mechanical procedures as described in the Ephodos as mathematically rigorous; and the use of indivisibles, as they appeared in Theorem 14, were equally suspicious as they involved the paradoxical notion of the infinite. Since the time of Zeno and Democritus, the paradoxes of the infinite had weighed heavily on Greek philosophy and mathematics, hence the method of exhaustion and its actual "limit avoidance," precluding any need to appeal to an actually infinite number of cases.

Nevertheless, we know that it is impossible to determine the volume of a pyramid, for example, with- out recourse to infinitary arguments, and likewise, to square the circle or find the volume of a sphere or the horse-shoe (toenail as Reviel Netz calls it). ${ }^{6}$ In Proposition 14, Archimedes depended on the application of an infinitary argument-one that set up a complex series of proportional lines which Archimedes could then show held for any plane or cut one might choose to make-even though there were an infinite number of such possible cuts to be made.

LIU Hui also considered the problem of finding a formula for the volume of the sphere, given its diameter. In Chapter 4 of the Nine Chapters, the diameter $d$ of a sphere of volume $V$ is given as $d=\sqrt[3]{(16 / 9) V}$. This result was known empirically, as a comment on this passage states: "a copper cube of diameter 1 cun weight 16 ounces, while a copper ball of the same diameter weight 9 ounces: this is the origin of the ratio 16:9." 7

LIU Hui explains this result as follows in his commentary. Consider a circle inscribed in a square. The circle is $3 / 4$ the area of the square. Now consider the cylinder inscribed in a cube. The ratio of the volumes must again be 3:4 (think of any plane cut through the cube parallel to the base; the ratio is always the same). If we assume the sphere inscribed in the cylinder is $3 / 4$ the volume of the cylinder, then the volume of the sphere is $3 / 4(3 / 4) d^{3}$ or $9 / 16$ of the volume of the cube; hence $d=\sqrt[3]{(16 / 9) V} \cdot 8$

But LIU Hui knows that this is not quite right, and tries to get a more precise result. He notes that the formula for the volume of the sphere as $3 / 4$ the volume of the cylinder would be exact if one considered not the sphere and cylinder, but another object with a volume less than the cylinder, which he called a 牟合方蓋 mouhe fangai, two "inverted umbrellas." 9

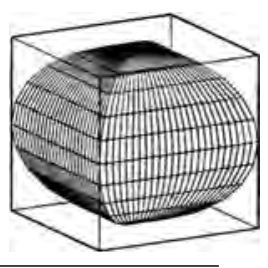

\footnotetext{
${ }^{6}$ See (Netz and Noel 2008). A more detailed account of the mathematics is given in (Tchernetska 2002: 109-125).

7 LIU Hui, commentary on the Nine Chapters, in (Qian Baocong 1963, vol. 1).

${ }^{8}$ LIU Hui, in (Qian 1963, vol. 1).

9 There is no agreement among historians of Chinese mathematics as to exactly how this phrase should be translated. Donald Wagner prefers Yan LI's interpretation (Li Yan 1963: 59) of the phrase mouhe fanggai, adding that "An anonymous referee of this article for Chinese Science suggested an alternative interpretation: 'a combination of a pair of covers on a common square base', mou meaning 'double' and he having its usual meaning, 'to combine'. This still leaves open the question of what sort of 'covers' these might be. The late Prof. Kurt Vogel pointed out to me the similarity of the geometric form under consideration here with the
} 


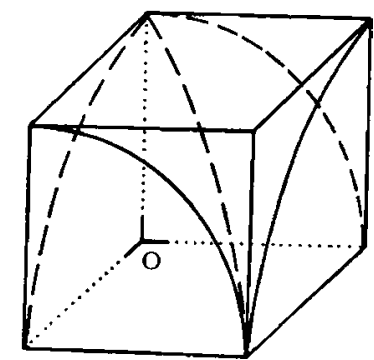

(a)

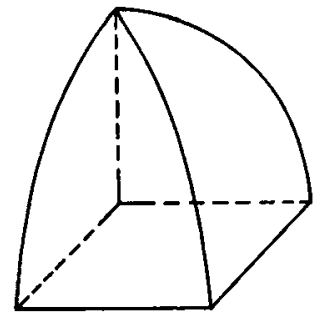

(b)

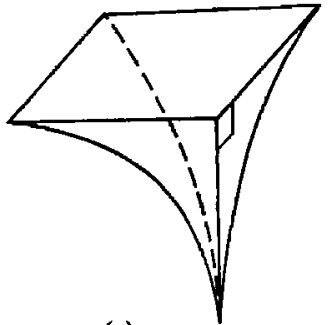

(c)

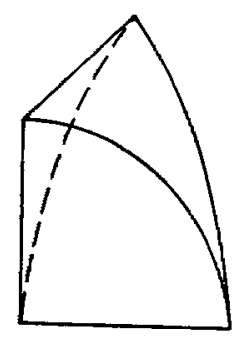

(e)

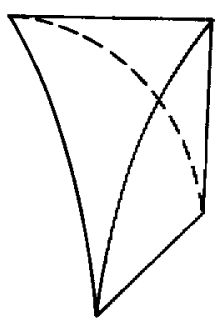

(d)
This in fact is the bicylinder-the same figure contemplated by Archimedes formed by the intersection of two cylinders at right angles to each other. Unfortunately, LIU Hui realized that he could not solve the problem of finding the exact volume of this figure, but two centuries later, the mathematician ZU Gengzhi managed to do so by considering $1 / 8$ of the cross section of the cube containing the bicylinder (eight of these together would constitute the entire

ancient bronze or ceramic vessel type called a fang 鉝. In the phrase mouhe fanggai the character 方 fang could be a loan character for this fang 鈁, and the phrase could be translated, 'a combined pair of fang 鈁-covers'. Bai Shangshu (《九章算術》 住釋 《Jiu zhang suanshu» zhushi (Annotated edition of Jiu zhang suanshu), Beijing: Kexue Chubanshe, 1983: 123) interprets the cover as an 'umbrella' (san 傘). Therefore Crossley's translation of Li Yan and Du Shiran (Li and Du, Chinese mathematics: A concise history, trs. John N. Crossley and Anthony W.-C. Lun, Oxford: Clarendon Press, 1987: 74, 85) translates mouhe fanggai as 'two square umbrellas'. J.-C. Martzloff (Histoire des mathématiques chinoises, Paris: Masson, 1988: 270) interprets gai 蓋 as 'vault' (in the architectural sense) rather than 'cover', so that the phrase could be translated, 'a double vault'." See (Wagner 1978: 59-79). See also the modified web-site version of this paper, from which the above has been quoted: http://www.staff.hum.ku.dk/dbwagner/Sphere/Sphere.html. Among other changes, the web version of Wagner's paper uses pinyin transliterations rather than the Wade-Giles transliterations to be found in the Chinese Science version of this paper. bicylinder, but since this is a symmetric figure, it suffices to consider the case shown here in figure (a).

ZU Gengzhi dissected this cube using the two cylindrical cuts, obtaining four pieces, one of which he called the "internal" piece (b) and three "external pieces" (c), (d), and (e).

Now, looking at any horizontal cross section through the cube, ZU Gengzhi examined the relation between the one "internal" cross sectional area (b) and the three "external" cross sectional areas (c), (d), and (e), and discovered that the area relations between the sections remained the same wherever the cross section might be taken, pointing out that "this is true whatever the height." ${ }^{\prime \prime}$

The crucial application of a "Cavallieri" principle then appears as follows:

The stacked 棋 qi (blocks) form the volumes, the shi of the areas being identical, the volumes cannot differ from one another. ${ }^{11}$

10 ZU Gengzhi, quoted from (Wagner 1978).

11 Wagner quotes ZU Gengzhi as follows:

墨棋成立積

緣崂势既同

則積不容異

If blocks are piled up to form volumes, And corresponding areas are equal, Then the volumes cannot be unequal. 


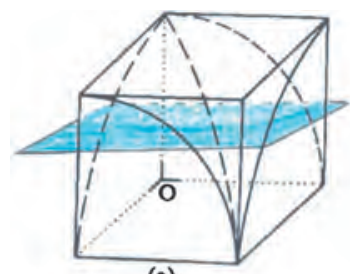

(a)

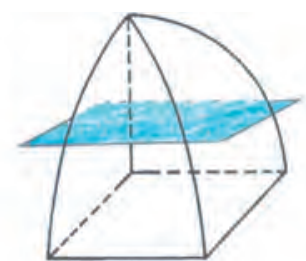

(b)

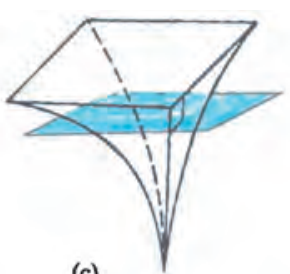

(c)

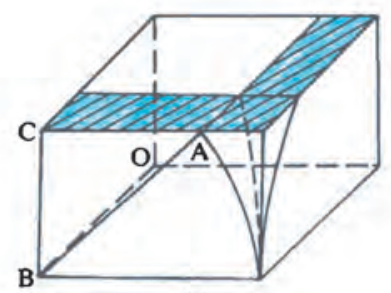

(f)

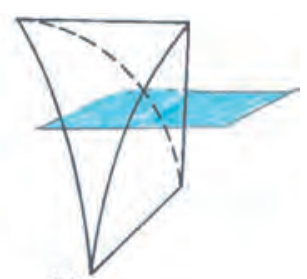

(d)

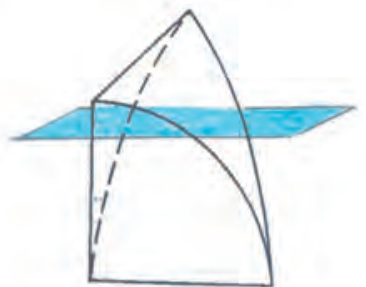

(e)

And what of the 棋 $q i$ here? Is this really an infinitesimal lamina, as the $18^{\text {th }}$-century commentator LI Huang has edited the text at this point to read $m i$ rather than qi? And is Donald Wagner right in agreeing that this should indeed be read as mi rather than $q i$, which would correct the text to mean an infinitesimal laminal surface or plane cut? Despite such questions, it seems clear that this gist of the argument ZU Gengzhi is making is a version of Cavallieri's principle.

\section{Conclusion}

In conclusion, how are we to account for this extraordinary example of what appears to be near simultaneous discovery - or should we say creation-of the same mathematical results and techniques by mathematicians working in disparate locations and cultures, but with the same intents and goals in mind? Both Archimedes and LIU Hui devoted their lives to mathematics. LIU Hui even realized there were problems he could not solve, but hoped one day they would be.

This now sets the stage for a comparison of the mathematics considered here, east versus west. Geoffrey Lloyd has suggested that one way to view the differences that distinguish Greek and Chinese thought is in terms of adversaries and authorities. By entitling his book comparing the two cultures as Adversaries and Authorities, Lloyd in a nutshell characterizes what he takes to be distinctive differences between science in ancient Greece and China. In short,

Here, instead of $q i$ in the first line, the $18^{\text {th }}$-century commentator LI Huang edited the text to read 幕 $m i$, amending the text to mean an infinitesimal laminal surface or plane cut. As Wagner remarks, "Though this statement might be understood in any number of ways, it is clear from the context that it is in fact a statement of Cavallieri's Theorem," and this seems a reasonable conclusion as I read this passage as well. See (Wagner 1978). if the examples may be the same, if you will, universal, in that we are dealing with right triangles, circles, inscribed polygons, spheres-whose mathematical properties may indeed by universal, especially if idealized in the same way, whether in Athens or Xi'an, one of the capitals of ancient China-the contexts in which those universals are considered indeed may differ greatly from ancient Greece to ancient China.

Lloyd sees the Greeks as developing their axiomatic approach to proof, including the paragon of their mathematical method with respect to the infinite in the method of exhaustion and the use of indirect proofs-namely the reliance on reduction $a d a b$ surdum methods-as growing out of the adversarial experiences of the Greek city states, the law courts, and democratic arguments necessary to convince political adversaries of the acceptability, the legitimacy of a given argument. The Chinese political context placed greater emphasis on authoritarian rule, and hence, Lloyd argues, there resulted a different sort of argumentation. Reliance on authority in turn impeded the progress of mathematics in China, or so this argument goes, whereas argumentation served to advance the subject in Greece.

But more to the point, I think, Chinese mathematicians were certainly willing to criticize bad or poor results. The interest in finding better and better approximations of the value of $p i$, or algorithms for extracting square and cube roots, are examples to consider. But Chinese mathematicians had little patience for a clever argument for the sake of argument; there are no examples of counter-factual reasoning in China, and when confronted by reduction ad absurdum premises, the Chinese reaction is "why begin by assuming something you know to be false?"12

12 For examples, see the interesting if controversial study by Alfred Bloom (Bloom 1981), and the review by Benjamin Elman (Elman 1983). 
It may be that the Chinese were more practically minded than the Greeks, and not interested in clever sophistry for the sake of argument, but closer to what constitutes the difference and character of reasoning east and west, rather than authorities versus adversaries, Yin versus Yang, I would emphasize the difference between consensus in China versus contrariness in ancient Greece, a comparison more aptly reflected in the recent comparative study of Geoffrey Lloyd and Nathan Sivin, The Way and the Word (Dao and $\lambda$ ó $\gamma o \varsigma$ ). Science and Medicine in Early China and Greece. ${ }^{13}$ The differences between the 道 dao and $\lambda$ ó $\gamma o \varsigma$ logos, consensus and argument, whether they be the result of sociological, political, or even psychological differences between east and west, is an open question for more detailed and serious investigation.

However, what is apparent from comparison of the mathematics of Archimedes and LIU Hui is that wherever the human mind may confront mathematics, and specific mathematical cases like circles or spheres-the goal is the same-to establish results, discover relationships, and to provide arguments not only for thier plausibility, but for their general validity, laws if you will, governing all circles and all spheres, whether they be in ancient Greece or China, or the contemporary mathematics classroom. As Plato understood, mathematics is one of the most remarkable and enduring achievements of the human mind.

\section{Glossary}

\section{Proper Names}

CAI Jixiang 蔡季襄

DAI Zhen 戴震

GUO Shirong 郭世榮

GUO Shuchun 郭书春

HORNG Wannsheng 洪萬生

HSU Kuang-Tai 徐光台

LI Cang 利沧

LI Chunfeng 李淳風

LI Huang 李潢

LI Xueqin 李学勤

LI Yan 李俨

LIU Hui 劉徽

LÜ Hou 吕后

PENG Hao 彭浩

QIAN Baocong 钱宝琮

Qin Shi Huang 秦始皇

SIMA Qian司馬遷

XIAO Can 肖灿

XIN Zhui 辛追

XU Yibao 徐义保

YANG Hui 楊輝

13 (Lloyd and Sivin 2002).
ZOU Dahai 邹大海

ZU Chongzhi 祖冲之

ZU Gengzhi 祖甠之

\section{Book Titles}

Ce liang quan yi 測量全義 (On the Measurement of the Circle) (Archimedes, 1635)

Er nian Lü ling 二年律令 (Statutes of the Second Year of the Lü Reign)

Hai dao suan jing 海島算經 (Sea Island Mathematical Manual)

Jiu zhang suan shu 九章算術 (Nine Chapter on the Art of Mathematics)

《Jiu zhang suanshu» zhushi 《九章算術》注释 (Annotated edition of Jiu zhang suan shu) (Bai Shangshu)

《九章算术》注释 《Jiu zhang suan shu》 zhushi (Commentaries and Explanations for the Nine Chapters on Mathematical Procedures).

Shu 數 (Numbers)

Shu shu 數術 (Numerals and Arts/Skills)

Suan jing shi shu 算經十書 (Ten Mathematical Classics)

Suan shu shu 算數書 (Book on Numbers and Computations)

Sunzi suan jing 孫子算經 (Mathematical Classic of Sun Zi)

Tian wen qui siang za zhan 天文氣象雜占 (Divination by Astrological and Meteorological Phenomena)

Wu shi er bing fang 五十二病方 (Prescriptions for 52 Diseases)

Wu xing zhan 五星占 (Divination by Five Stars)

Xiangjie Jiuzhang suanfa 詳解九章算法 (Detailed Explanations of the Nine Chapters of Computational Procedures)

Yongle dadian 永樂大典 (Yongle Encyclopedia),

Zhou bi suan jing 周髀算經 (Computational Classic of the Zhou Gnomon)

Zhou yi 周易 (Book of Changes, the Yi jing)

\section{Institutional and Place Names}

Bing ma yong 兵马俑 (Terracotta warriors)

Chu boshu 楚帛書 (Chu silk manuscript)

Chutu wenxian yanjiu yu baohu zhongxin 出土文献研究与保护中心 (Center for Excavated Texts Research and Preservation, Tsing-Hua University, Beijing)

Liye gucheng Qindai jiandu 里耶古城秦代简牍 (Liye Ancient City Qin Dynasty Bamboo Documents)

Mawangdui 馬王堆 (Changsha, Hunan)

Qinghua jian 清华简 (Tsinghua Bamboo Slips)

Shuihudi Qin jian 睡虎地秦简 (Qin Bamboo Slips from Shuihudi, Hubei)

Tsinghua University, Beijing 清华大学 
Yuelushuyuan cang Qinjian 获麓書院藏秦簡 (Qin Slips Collected by the Yuelu Academy)

Zhangjiashan Han jian 張家山漢簡 (Han Bamboo Slips from Zhangjiashan, Hubei)

\section{Miscellaneous terminology}

Dao 道 (The Way)

$\mathrm{Fu}$ 負 (to carry)

Fu tan 負炭 (transporting charcoal)

Gai 蓋 (vault)

Gou 句 (shorter leg of a right triangle)

$\mathrm{Gu}$ 股 (longer let of a right triangle)

Guan 官 (government post)

Ji yue 即曰 (it says)

Kai fang shu 開方術 (Method of Finding the Square Root)

Lu tang 盧唐 (bamboo ladles/utensils)

Mi 幕 (infinitesimal laminal surface/ plane cut)

Mi lü 密率 (more accurate rate)

Mouhe fanggai 牟合方蓋 (two “inverted umbrellas”)

Qi 棋 (blocks)

Shu yue 术曰 (the method says)

Su mi 粟米 (millet and rice/grains)

Shi ru fa de yi dou 實如法得一斗(dividing gives the answer in dou)

Shui tian 税田 (farmland)

Suan shu 算數 (numbers and computations/reckoning)

Wei shi 爲實 (as the dividend)

Xian 弦 (the hypotenuse of a right triangle)

Yi qiu jisuan bianjie 以求計算便捷 (to facilitate the computation of that which is sought)

Yu shi 羽矢 (feathering arrows)

\section{References}

Bai, Shangshu (白尚恕). 《九章算术》与刘徽的几何理论 《Jiu zhang suan shu» yu Liu Hui de jihe lilun (The Geometrical Principles of the Jiuzhang suanshu and Liu Hui). In 《九章算术》与刘徽 《Jiu zhang suan shu» yu Liu Hui (The Jiu zhang suan shu and Liu Hui), 吴文俊Wenjun WU, ed. Beijing: Shifan Daxue Chubanshe, 1982: 137-161.

Bai, Shangshu (白尚恕). 《九章算术》注释 《Jiu zhang suan shu» zhushi (Annotated edition of Jiu zhang suan shu). Beijing: Kexue chubanshe, 1983.

Berlin, J. "World's Oldest Decimal Times Table Found in China." National Geographic (April 5, 2014): http://news. nationalgeographic.com/news/2014/04/140405-chineseoldest-multiplication-table-decimal/.

Black, M. and Davidson, R. Constantin von Tischendorf and the Greek New Testament. Glasgow: University of Glasgow Press, 1981.

Bloom, A. The Linguistic Shaping of Thought: A Study in the Impact of Language on Thinking in China and the West. Hillsdale, N.J.: Erlbaum Associates, 1981.

Burnet, J. The Fragments of Heraclitus. London, 1920.

Chemla, K. "What is at Stake in Mathematical Proofs from Third-Century China?" Science in Context 10 (2) (1997): 227-251.
Chemla, K. "Fractions and Irrationals between Algorithm and Proof in Ancient China," Studies in History of Medicine and Science 15 (1-2) (1997-1998): 31-54.

Cullen, C. “Chiu chang suan shu 九章算術.” In Early Chinese Texts: a Bibliographical Guide, Michael Loewe, ed. Early China Special Monograph Series 2. Berkeley: Society for the Study of Early China, Institute of East Asian Studies, University of California, 1993.

Cullen, C. "Learning from Liu Hui? A Different Way to Do Mathematics." Notices of the American Mathematical Society 49 (7) (2002): 783-790.

Cullen, C. "The Suan shu shu 等數書 'Writings on reckoning': A translation of a Chinese mathematical collection of the second century BC, with explanatory commentary." Needham Research Institute Working Papers 1. Cambridge: Needham Institute, 2004.

Dauben, J. W. “算數書 Suan Shu Shu (A Book on Numbers and Computation). English Translation, Notes and Critical Commentary." Archive for History of Exact Sciences 62 (2) (2008): 91-178.

Dauben, J. W., Guo, S. and Xu, Y. 九章等術 Nine Chapters on the Art of Mathematics. A Critical Edition and English Translation based upon a New Collation of the Ancient Text and Modern Chinese Translation. Shenyang: Liaoning Education Press, 2013.

Du, Shiran (杜石然). 祖暅之公理 Zu Gengzhi gongli (The Axiom of Zu Gengzhi), 数学通报 Shuxue tongbao 3 (1954): 9-11.

Elman, B. A. Review of (Bloom 1981). In The Journal of Asian Studies 42 (3) (1983): 611-614.

Feng, L. and Xu, Y. "The Tsinghua Multiplication Table." Mathematical Knowledge at Work in Ancient China, Special Symposium S115-A of the Twenty-Fourth International Congress of History of Science, Technology and Medicine, The University of Manchester, UK, July 23, 2013. http://www.ichstm2013.com/programme/guide/i/ 10953.html.

Guo, Shirong (郭世榮). 《算數書》勘误 《Suan shu shu» kanwu (Corrections for the Suan shu shu), Journal of Inner Mongolia Normal University 30 (3) (2001): 276-285.

Guo, Shuchun (郭书春). 匯校《九章算术》Huijiao 《Jiu zhang suan shu» (A Critical Textual Study of the Nine Chapters on Mathematical Procedures). Shenyang: Liaoning jiaoyu chubanshe, 1990.

Guo, Shuchun (郭书春), ed. 中国科学技术典籍通汇: 数学卷 Zhongguo kexue jishu dianji tonghui: Shuxue juan (A Compendium of Chinese Classics of Science and Technology: Mathematics Section), 5 vols. Zhenzhou: Henan jiaoyu chubanshe, 1993.

Guo, Shuchun (郭书春). 算數書校勘 Suan shu shu jiaokan (Collation of the Suan shu shu), 中国科技史料 Zhongguo kexu shiliao (China Historical Materials of Science and Technology), 22 (3) (2001): 202-219.

Heiberg, J. L. Geometrical Solutions Derived from Mechanics. A Treatise of Archimedes. Chicago: Open Court, 1909.

Horng, Wannsheng (洪萬生). 古代中國的幾何學 Gudai Zhongguo de jihexue (Geometry in Ancient China), 科學月刊 Kexue yuekan (Science Monthly) 12 (1981): 22-30.

Hulswé, A. F. P. "Weights and Measures in Ch'in Law." In State and Law in East Asia. Festschrift Earl Bünger, Dieter Eikemeier and Herbert Franke, eds. Wiesbaden: Otto Harrassowitz, 1981: 25-39.

Kiang, T. "An old Chinese way of finding the volume of a sphere." The Mathematical Gazette 56 (1972): 88-91.

Kirk, G. S. The Cosmic Fragments/Heraclitus. Cambridge, UK: Cambridge University Press, 1954.

Knobloch, E. "Commentary on 'Cleomedes and the Measurement of the Earth: A Question of Procedures' by Alan C. Bowen, Centaurus 2003, 45, pp. 59-68." Centaurus 50 (1-2) (2008): 205. 
Lam, Lay-Yong (蓝丽蓉). “Jiu Zhang Suanshu 九章算術 (Nine Chapters on the Mathematical Art): An Overview." Archive for History of Exact Sciences 47 (1) (1994): 1-51.

Lam, L.-Y. and Shen, K. "The Chinese Concept of Cavalieri's Principle and its Applications." Historia Mathematica 12 (1985): 219-228.

Li, L. and Cook, C. A. "Translation of the Chu Silk Manuscript." In Defining Chu: Image and Reality in Ancient China, Constance A. Cook and John S. Major, eds. Honolulu: Hawaii University Press, 1999: 171-176.

Li, Yan (李傮). 中國算學史 Zhongguo suanxue shi (The History of Mathematics in China). Shanghai: Shangwu Yinshuguan. 1937; repr. 1954.

Li, Yan (李谖). 中國古代數學史料 Zhongguo gudai shuxue shiliao (Historical Materials on Ancient Chinese Mathematics). Shanghai: Shanghai Kexue Jishu Chubanshe, 1954; second ed. 1963.

Li, Yan (李㒈) and Du, Shiran (杜石然). A Concise History of Chinese Mathematics, John N. Crossley and Anthony W.-C. Lun, trans. Oxford: Clarendon Press: 1987.

Lloyd, G. E. R. Adversaries and Authorities. Investigations into Ancient Greek and Chinese Science. Cambridge, England: Cambridge University Press, 1996.

Lloyd, G. E. R. and Sivin, N. The Way and the Word (道 dao and $\lambda$ ó $\gamma o \varsigma$ logos). Science and Medicine in Early China and Greece. New Haven: Yale University Press, 2002.

Loewe, M. Records of Han Administration, vol 2: Documents. Cambridge, England: Cambridge University Press, 1967.

Martzloff, J.-C. Histoire des mathématiques chinoises. Paris: Masson, 1987.

Martzloff, J.-C. A History of Chinese Mathematics. Stephen S. Wilson, trans. Berlin: Springer, 1997; rev. ed. 2006.

Mikami, Yoshio (三上義夫). The Development of Mathematics in China and Japan (Abhandlugen zur Geschichte der mathematischen Wissenschaften 30 (1913)); repr. New York: Chelsea, 1961.

Needham, J. and Wang, Ling (王铃). Science and Civilisation in China. Vol. 3. Mathematics and the Sciences of the Heavens and the Earth. Cambridge: Cambridge University Press, 1959.

Netz, R. and Noel, W. The Archimedes Codex. How a medieval prayer book is revealing the true genius of antiauity's greatest scientist. Cambridge, MA: Da Capo Press, 2007.

Netz, R., Saito, K., and Tchernetska, N. "A New Reading of Method Proposition 14: Preliminary Evidence from the Archimedes Palimpsest (Part 1)." Sciamvs 2 (2001): 9-29; and Reviel Netz, Ken Saito, and Natalie Tchernetska. "A New Reading of Method Proposition 14: Preliminary Evidence from the Archimedes Palimpsest (Part 2)." Sciamvs 3 (2002): 109-125.

Peng, Hao (彭浩). 中国最早的数学著作《算数书》. Zhongguo zuizao de shuxue zhuzuo «Suan shu shu» (The Earliest Arithmetic Book in Chinese), 文物 Wenwu (Cultural Relics), 9 (2000): 85-90.

Peng, Hao (彭浩). 张家山漢简《算数書》註釋 Zhangjiashan hanjian «Suan shu shu» zhushi (Commentary and Explanation of the Suan shu shu on Bamboo Strips from Zhangjiashan). Beijing: Kexue chubanshe, 2001.

Qian, Baocong (钱宝琮), ed. 算经十书 Suanjing shishu (Ten Mathematical Classics). Beijing: Zhonghua Shuju, 1963.

Qian, Baocong (钱宝琮). 中国数学史 Zhongguo shuxue shi (The History of Mathematics in China). Beijing: Kexue Chubanshe, 1964.

Qiu, J. "Ancient Times Table Hidden in Chinese Bamboo Strips.” Nature (January 7, 2014): http://www.nature. com/news/ancient-times-table-hidden-in-chinese-bamboostrips-1.14482.
Sato, T. “A Reconstruction of The Method Proposition 17, and the Development of Archimedes' Thought on Quadrature-Why did Archimedes not notice the internal connection in the problems dealt with in many of his works?" Historia Scientiarum 31 (1986): 61-86.

Seidenberg, A. "On the Volume of a Sphere." Archive for History of Exact Sciences 39 (1988/89): 97-119.

Shen, Kangshen (沈康身). The Nine Chapters on the Mathematical Art: Companion and Commentary. John N. Crossley and Anthony W.-C. Lun, trans. Oxford: Oxford University Press, 1999.

Swetz, F. J. and Kao, T. I. Was Pythagoras Chinese? An Examination of Right Triangle Theory in Ancient China. University Park, PA: The Pennsylvania State University Press, 1977.

Taisbak, C. M. Historia Mathematica. Mailing List Archive: 23 Jun 1999 19:32:38 +0200 [http://sunsite.utk.edu/math_ archives/.http/hypermail/historia/jun99/0149.html].

Tongxun 2000. Yiwen Su 蘇意雯, Junhong Su 蘇俊鴻, Huiyu Su 蘇惠玉, Fengzhu Chen 陳鳳珠, Cangyi Lin 林倉億, Qingyang Huang 黃清陽, and Jihai Ye 葉吉海. 《算數書》校勘 Suan shu shu jiaokan (Collation of the Suan shu shu). HPM 通訊 HPM tongxun (HPM Newsletter), 3 (11) (2000): 2-20.

van der Waerden, B. L. Geometry and Algebra in Ancient Civilizations. Berlin: Springer-Verlag, 1983.

Volkov, A. "Geometrical Diagrams in Traditional Chinese Mathematics." In Graphics and Text in the Production of Technical Knowledge in China. The Warp and the Weft, Francesca Bray, Vera Dorofeeva-Lichtmann, and Georges Metailie, eds. Leiden: Brill, 2007: 425-460.

Wagner, D. "Liu Hui and $\mathrm{Zu}$ Gengzhi on the Volume of a Sphere." Chinese Science 3 (1978): 59-79.

Wagner, D. "Doubts concerning the attribution of Liu Hui's commentary on the Chiu-chang suan-shu." Acta Orientalia (Copenhagen), 39 (1978): 199-212.

Wagner, D. "An early Chinese derivation of the volume of a pyramid: Liu Hui, third century A.D." Historia Mathematica 6 (1979): 164-188.

Wu, Wenjun (Wentsun) (吴文俊). “The out-in complementary principle." In Ancient China's Technology and Science, Institute for the History of Natural Sciences, Chinese Academy of Sciences, ed. Beijing: Foreign Languages Press, 1983: $66-89$

WW 2000. 江陵張家山漢簡整理小組 Jiangling Zhangjiashan Hanjian zhengli xiaozu (Study Group for the Collation and Arrangement of the Han Dynasty Bamboo Slips from Zhangjiashan, Jiangling County), ed. 江陵張家山漢簡《算數書》釋文 Jiangling Zhangjiashan Hanjian «Suan shu shu» shiwen (Transcription of the Bamboo Suanshushu or A Book of Arithmetic from Jiangling), 文物 Wenwu (Cultural Relics), 9 (2000): 78-84.

Wylie, A. "Jottings on the Science of Chinese Arithmetic." In North China Herald (August-November, 1852); reprinted in (Wylie 1897: 159-194).

Wylie, A. Chinese Researches. Shanghai: n.p., 1897; repr. Taipei: Ch'eng-Wen Publishing, 1966. http://babel. hathitrust.org/cgi/pt?id=mdp.39015058016513\#page/ n8/mode/1up (accessed January, 2013).

Xiao, Can (肖灿). 获麓書院藏秦簡《數》研究 Yuelushuyuan zang Qinjian «Shu» yanjiu (A Study of the Qin Bamboo Book on Numbers Preserved in the Yuelu Academy). Dissertation: Hunan University, 2010.

Yang, Hui (杨辉). 詳解九章算法 Xiangjie ziuzhang suanfa (Detailed Explanation of the Computational Methods in the Nine Chapters). 1261. Reproduced in (Guo 1993, vol. 1).

ZJS: Zhangjiashan. 張家山二四七號漢墓竹簡整理小組 Zhangjiashan ersiqi hao Hanmu zhujian zhengli xiaozu (Study 
Group for the Collation and Arrangement of the Bamboo Slips from Zhangjiashan Han Dynasty Tomb 247), ed. 張家山漢墓竹簡 Zhangjiashan Hanmu zhujian (Bamboo Strips from Han Tombs at Zhangjiashan). Beijing: Wenwu chubanshe, 2001: 83-96; 249-272.

Zou, Dahai (邹大海). 出土《算數書》初探 Chutu «Suan shu shu» chu tan (Preliminary Research on the Unearthed Mathematics Book Suan shu shu). 自然科學史研究 Ziran kexueshi yanjiu (Studies in the History of Natural Sciences), 20 (3) (2001): 193-205.

Zou, Dahai (邹大海). "Shuihudi bamboo strips of the Qin Dynasty and mathematics in Pre-Qin Period." Frontiers of History in China 2 (4) (2007a): 632-654.

Zou, Dahai (邹大海). "Shuihudi's Bamboo Strips of Qin Dynasty and Mathematics in Pre-Qin Period." Chinese Archaeology 7 (2007b): 132-136. 